Research paper

\title{
Synthesis and SAR evaluation of novel thioridazine derivatives active against drug-resistant tuberculosis
}

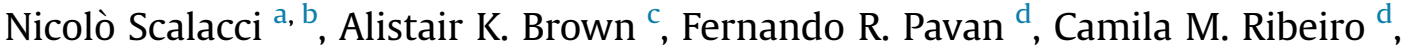 \\ Fabrizio Manetti ${ }^{\mathrm{e}}$, Sanjib Bhakta ${ }^{\mathrm{f}}$, Arundhati Maitra ${ }^{\mathrm{f}}$, Darren L. Smith ${ }^{\mathrm{b}}$, Elena Petricci ${ }^{\mathrm{e}}$, \\ Daniele Castagnolo ${ }^{\text {a, }}$ \\ a Institute of Pharmaceutical Science, King's College London, 150 Stamford Street, London, SE1 9NH, United Kingdom \\ ${ }^{\mathrm{b}}$ Northumbria University Newcastle, Department of Applied Sciences, Ellison Building, Ellison Place, NE1 8ST, Newcastle upon Tyne, United Kingdom \\ c School of Medicine, Pharmacy and Health, Durham University, Wolfson Research Institute, Queens Campus, Stockton on Tees, TS17 6BH, United Kingdom \\ d São Paulo State University (UNESP), School of Pharmaceutical Sciences, Araraquara, Brazil \\ e Dipartimento di Biotecnologie, Chimica e Farmacia, Via A. Moro 2, 53100, Siena, Italy \\ ${ }^{\mathrm{f}}$ Mycobacteria Research Laboratory, Department of Biological Sciences, Institute of Structural and Molecular Biology, Birkbeck, University of London, Malet \\ Street, London, WC1E 7HX, United Kingdom
}

\section{A R T I C L E I N F O}

Article history:

Received 24 November 2016

Received in revised form

19 December 2016

Accepted 21 December 2016

Available online 23 December 2016

Keywords:

Thioridazine

Tuberculosis

MDR-TB

Efflux pump

Indole

\begin{abstract}
A B S T R A C T
The neuroleptic drug thioridazine has been recently repositioned as possible anti-tubercular drug. Thioridazine showed anti-tubercular activity against drug resistant mycobacteria but it is endowed with adverse side effects. A small library of thioridazine derivatives has been designed through the replacement of the piperidine and phenothiazine moieties, with the aim to improve the anti-tubercular activity and to reduce the cytotoxic effects. Among the resulting compounds, the indole derivative 12e showed an antimycobacterial activity significantly better than thioridazine and a cytotoxicity 15-fold lower.
\end{abstract}

(c) 2016 Elsevier Masson SAS. All rights reserved.

\section{Introduction}

According to the recent World Health Organization annual report, tuberculosis (TB) remains one of the deadliest communicable infections [1]. Nearly one third of the worldwide population is latently infected with Mycobacterium tuberculosis (MTB), the etiological agent of tuberculosis in humans, and almost 9 million people develop active TB infections per annum. In addition, $14.8 \%$ of global TB patients are co-infected with HIV and can be credited as one of the most common causes of death among AIDS patients $[2,3]$. This global scenario is due to many causes including the lack of rapid diagnostic tools, the non-compliance of hospitalised patients to the 6-12 months multidrug therapy and institutions lacking the proper drug regimens to treat all the people infected [4]. As a consequence of these transgressions, and after half a century of

\footnotetext{
* Corresponding author.

E-mail address: daniele.castagnolo@kcl.ac.uk (D. Castagnolo).
}

little to no innovation in the field, MTB have developed multi-drug resistant (MDR) [5-7], extensively-drug resistant (XDR) [8] and totally-drug resistant (TDR) [9] strains, which are resistant to almost all the known available drugs. In 2012, the quinoline derivative bedaquiline $[10,11]$ became the first new drug launched in the market in the last 40 years, since the discovery of rifampin. Currently a number of lead molecules are in clinical trials, such as the diamine SQ109 [12], the fluoroquinolone gatifloxacin [13] and the linezolid [14]. However, the conventional therapeutic approach potentially exacerbates the incidence of new MDR-TB strains and therefore it is inevitable that MTB will evolve resistance against these novel drugs $[15,16]$.

Conventional drug discovery approaches need the identification of a specific target for the development and optimization of a specific molecule. However, it is well known that singular mutations of the targets active site could result in the nullification of drug activity [17]. The current treatment of TB involves the administration of several drugs simultaneously, this reduces the 
incidence of resistant MTB strains by avoiding single point mutations resistances against singular treatments. However, several side effects and poor patient compliance are associated with the present multiple therapy. A potentially successful approach to defeat TB is to discover a drug capable of inhibiting multiple MTB targets simultaneously whilst also retaining activity against MDR and latent TB with an ultimate objective of shortening the current TB regimens.

Thioridazine (TZ) 1, a long established neuroleptic drug, has been recently repositioned as anti-tubercular drug finding application in the treatment of MDR-TB $[18,19]$. TZ is currently used in therapy as a third line anti-tubercular drug due to the side-effects on the central nervous system and cardiovascular system which restrict its clinical use [20]. Despite the mechanism of action of TZ having not been fully elucidated, recent studies showed that it inhibits efflux pumps in mycobacteria and alters the cell-envelope permeability of MTB [21-23]. Furthermore, TZ $\mathbf{1}$ is able to affects the physiology of alveolar macrophages, enhancing the retention of potassium ions and promoting the acidification of phagolysosomal vacuole [24], finally leading to the degradation of intramacrophagic MTB.

Despite the chemistry and structure-activity relationship (SAR) properties of TZ, and related neuroleptic drugs, having been widely investigated in the past, to the best of our knowledge no drug derivatization and optimization studies have been carried out on $\mathrm{TZ}$ analogues as inhibitors of MTB.

Herein, we report the synthesis, biological evaluation and SAR studies of a narrow library of novel $\mathrm{TZ}$ derivatives. In particular, we aimed at the design and identification of novel TZ analogues with improved activity against TB and MDR-TB strains as well as reduced cytotoxic effects. Three series of derivatives were planned in order to explore the chemical space around the TZ nucleus, as shown in Fig. 1. In the first series, the $N$-methyl substituent on the piperidine ring was removed or replaced with different alkyl groups to evaluate its importance for anti-tubercular activity. In the second series, the piperidine ring of $\mathrm{TZ}$ was replaced with different aliphatic heterocyles, keeping fixed the distance between the piperidine nitrogen and the phenothiazine ring.

The role of the thiomethyl group attached to the phenothiazine
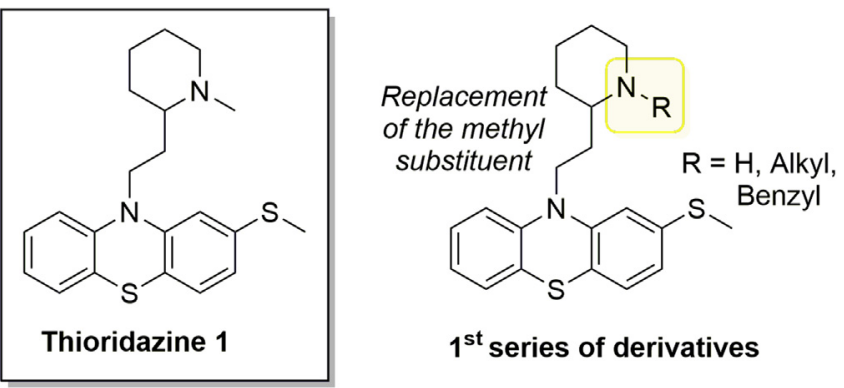

$$
1^{\text {st }} \text { series of derivatives }
$$
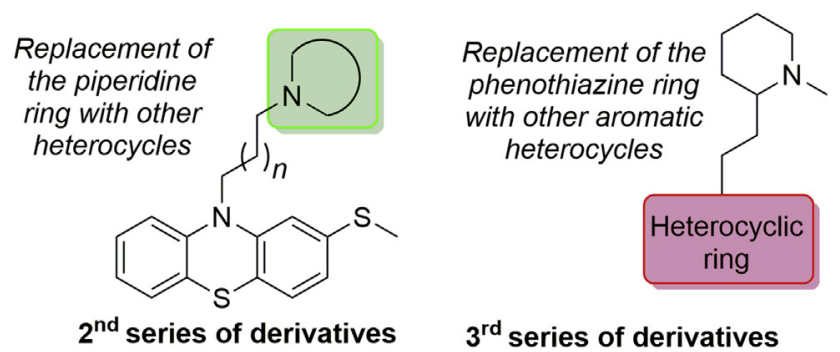

$2^{\text {nd }}$ series of derivatives ring was also investigated in this series. Finally, in the third series the phenothiazine core, which is responsible for the main side effects on the nervous system, was replaced with different heteroaromatic rings, with the aim to reduce the toxicity of the molecule.

\section{Results and discussion}

\subsection{Chemistry}

A series of N-substituted derivatives 4a-c was first synthesised. TZ was successfully demethylated by treatment with 1-chloroethyl-chloroformate in refluxing DCE [25] followed by hydrolysis with $\mathrm{MeOH}$ under reflux, leading to derivative 3 . Reductive amination of $\mathbf{3}$ with different aldehydes/ketones led to the final $\mathrm{N}$ alkyl-derivatives 4a-c in good yields (62-68\%). Scheme 1.

A second series of derivatives where the piperidine ring was replaced with different piperazine and thiomorpholine groups was then synthesised (Table 1). In addition, the thio-methyl substituent on the phenothiazine ring was removed or replaced with chlorine, to evaluate its importance for the anti-tubercular activity.

In particular, the chlorine substituent was chosen on the basis of similarity with chlorpromazine, a phenothiazine derivative closely related to TZ whose efflux pumps inhibitory activity is well known. In detail, the phenothiazines $\mathbf{5 a - c}$ were first reacted with 1-bromo3-chloropropane to yield the chloroderivatives $\mathbf{6 a - c}$ which were in turn treated with different piperazines and with thiomorpholine to yield the desired products 7a-i. The thio-methyl-phenothiazine 5a was also reacted with 2-chloroacetyl chloride leading to $\mathbf{8}$, which was in turn converted into derivatives 9a-b by treatment with methylpiperazine or piperidine.

Finally, the third series of compounds bearing the ethyl-<smiles>CSc1ccc2c(c1)N(CCC1CCCCN1C)c1ccccc1S2</smiles>

1<smiles>[R]C([R])N1CCCCC1CCN1c2ccccc2Sc2ccc(SC)cc21</smiles>

4a $\mathrm{R}=\mathrm{Ph}, \mathrm{R}_{1}=\mathrm{H}$

4b $R=E t, R_{1}=H$

4c $\mathrm{R}=\mathrm{Me}, \mathrm{R}_{1}=\mathrm{Me}$<smiles>CSc1ccc2c(c1)N(CCC1CCCCN1C(=O)OC(C)Cl)c1ccccc1S2</smiles>

2<smiles>CC#CC1CCCCN1CCN1c2ccccc2Sc2ccc(SC)cc21</smiles>

3
Scheme 1. Synthesis of analogues 4a-c. Reagents and conditions: $i$. 1-chloro-ethylchloroformate, DCE, Et ${ }_{3} \mathrm{~N}$, reflux, 12 h; ii. $\mathrm{MeOH}$, reflux, $12 \mathrm{~h}$; iii. $\mathrm{NaBH}(\mathrm{AcO})_{3}, \mathrm{THF}$, $\mathrm{AcOH}$, benzaldehyde for $\mathbf{4 a}$, or propionaldehyde for $\mathbf{4 b}$, or acetone for $\mathbf{4 c}$.

Fig. 1. General structures of the thioridazine analogues. 
Table 1

Synthesis of the compounds 7a-i and $\mathbf{9 a - b}$.

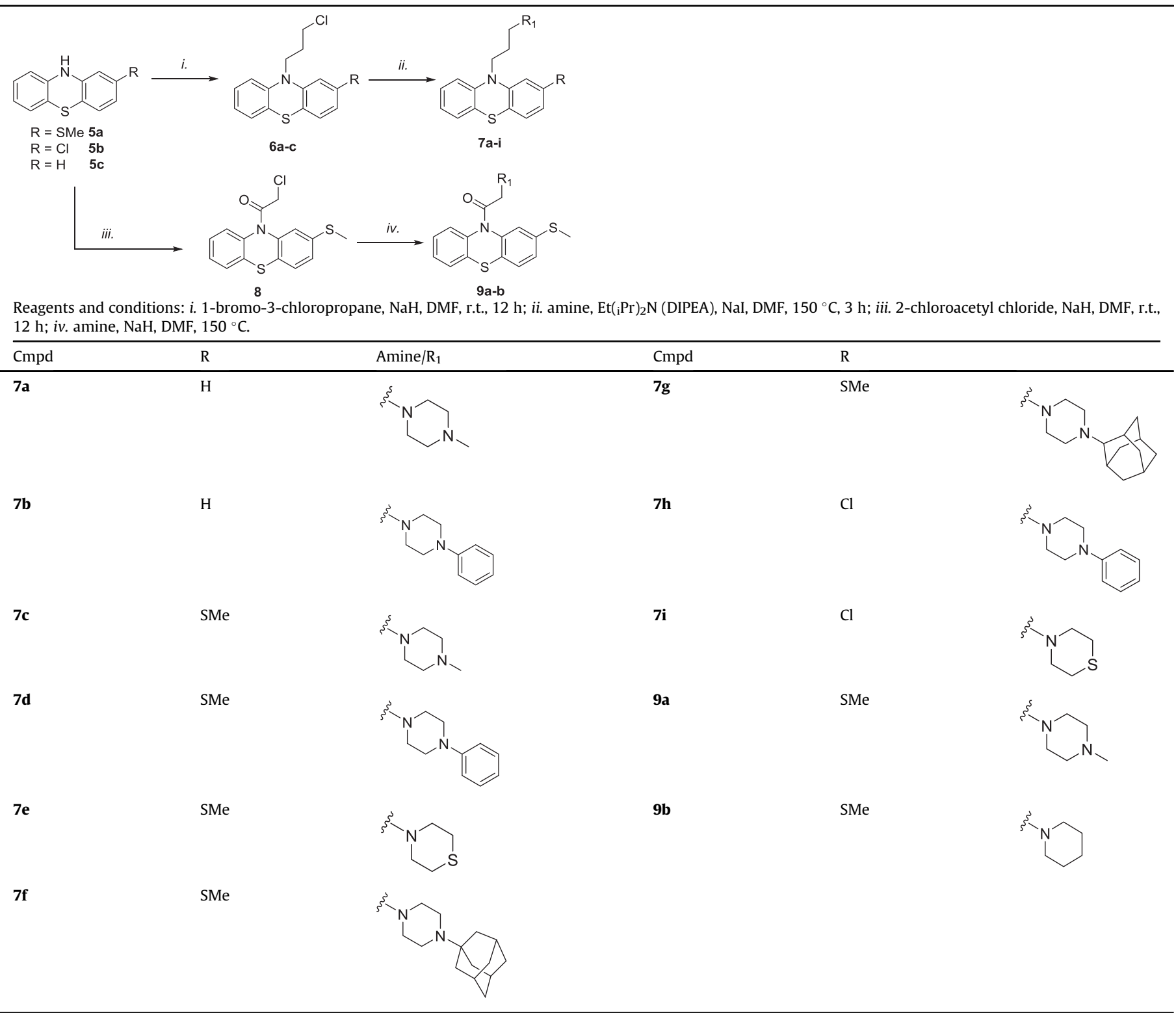

piperidine chain of TZ bound to different aromatic heterocycles was synthesised. Scheme 2.2-(Piperidin-2-yl)ethanol 10 was converted into the Boc-bromoderivative $\mathbf{1 1}$ by treatment with (Boc) $)_{2} \mathrm{O}$ followed by reaction with $\mathrm{CBr}_{4}$. Different heteroaromatic compounds (namely phenothiazine, 2-Cl-phenothiazine, carbazole, indole, and benzimidazole) were then alkylated with $\mathbf{1 1}$ and the resulting intermediates were deprotected with TFA yielding the 12a-e series of compounds. $\mathrm{N}$-methylation of $\mathbf{1 2}$ through reductive amination led to the methyl derivatives 13a-d [26]. Finally, 16, bearing an indole nucleus and a piperazine ring as the aliphatic side chain, were synthesised. Indole 14 was converted into the $\mathrm{N}$-chloro-propyl derivative 15, which yielded the final compound $\mathbf{1 6}$ after treatment with $N$-methyl-piperazine.

\subsection{Biological evaluation}

All the compounds were initially evaluated for their activity against a panel of non-pathogenic mycobacteria strains (namely, M. smegmatis $\mathrm{mc}^{2} 155$, M. bovis BCG and M. tuberculosis $\mathrm{mc}^{2} 7000$, as shown in Table 2).

A SAR analysis showed that removal of the methyl group of thioridazine did not affect the activity, the desmethyl-thioridazine $\mathbf{3}$ showing an activity similar to that of $\mathbf{1}$. Also the introduction of a benzyl chain as in $\mathbf{4 b}$ maintained a similar activity. On the other hand, the replacement of the piperidine-ethyl moiety with alkyl chains bearing piperazine or thiomorpholine rings as in $\mathbf{7}$ and $\mathbf{9}$ led to a dramatic decrease of antimycobacterial activity, with the only exception of the bulky derivative $7 \mathrm{~g}$ which showed a MIC $=4 \mu \mathrm{g}$ / $\mathrm{mL}$ on $M$. smegmatis. Moreover, removal of the methylthio substituent of $\mathbf{1}$ and $\mathbf{3}$ (as in 13a and 12a), as well as replacement of the 


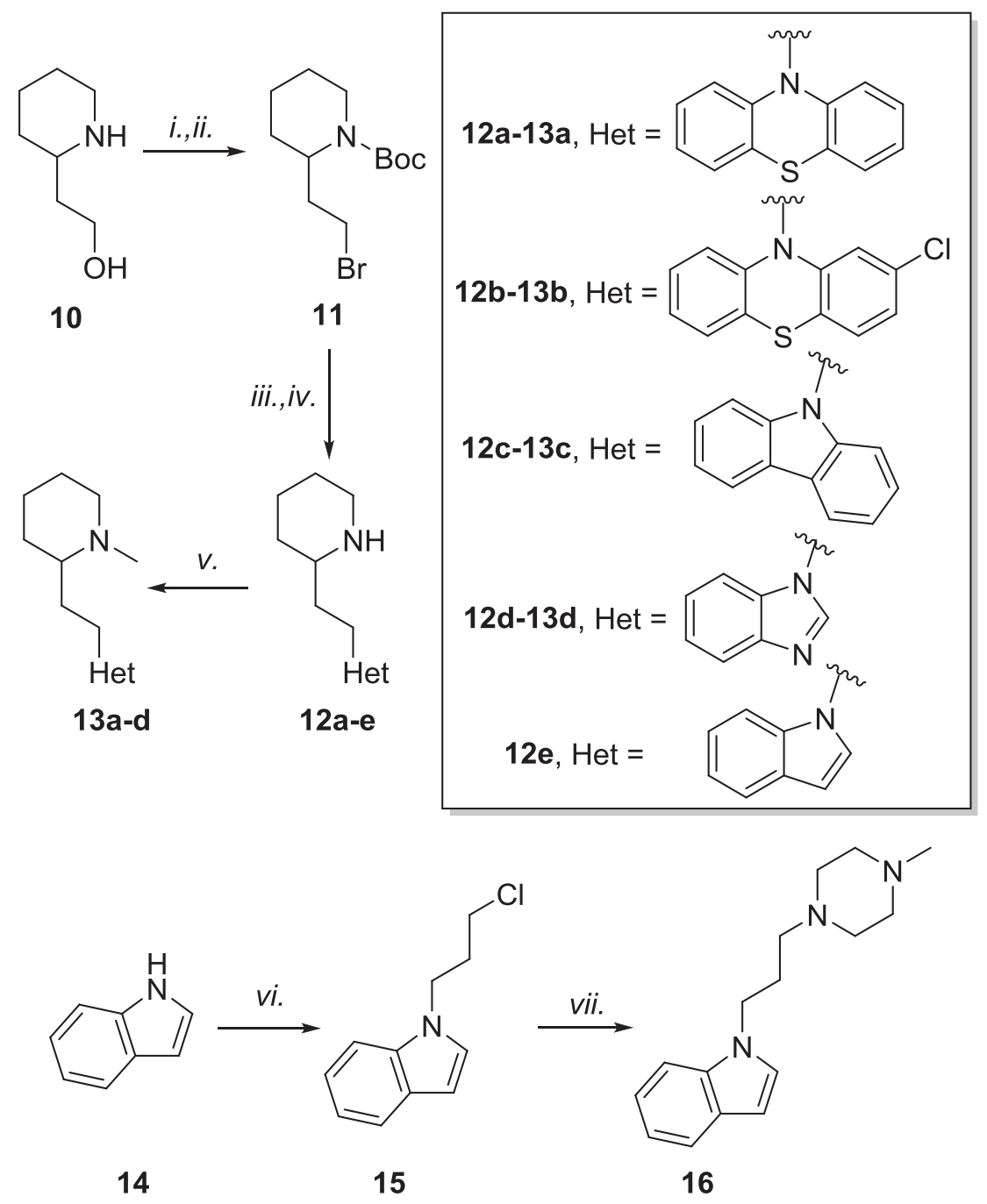

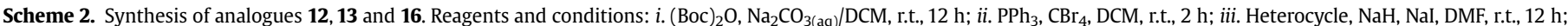

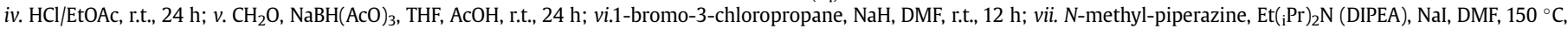
$3 \mathrm{~h}$.

phenothiazine scaffold with different heterocyclic moieties (as in 13c-d and 12c-d) led to a significant loss in activity.

On the contrary, replacement of the same SMe group with a chloride group (as in 12b and $\mathbf{1 3 b}$ ), as well as replacement of the entire phenothiazine moiety with an indole nucleus as in 12e resulted in compounds with an antimycobacterial activity comparable to or better than that of $\mathbf{1}$ and $\mathbf{3}$. In particular, the chlorophenothiazine derivative 12b showed a good activity against $M$. bovis BGC and $M$. tuberculosis $\mathrm{mc}^{2} 7000$ strains with MIC $=5.3 \mu \mathrm{g} / \mathrm{mL}$ and $4 \mu \mathrm{g} / \mathrm{mL}$, respectively. Similarly, the methylated analogue 13b retained a $8 \mu \mathrm{g} / \mathrm{mL}$ MIC value. Interestingly, the indole derivative 12e proved to be highly active against M. smegmatis with MIC $=1.6 \mu \mathrm{g} / \mathrm{mL}$.

The most promising compounds were then assayed against the pathogenic H37Rv strain, the drug-susceptible CF73 clinical isolate, and two MDR-clinical isolates (CF104 and CF81). Also in this case, 12b, 12e, and 13b showed the best results. In particular, the chloroderivatives 12b and 13b had an activity toward the CF73 and the MDR strains similar to that of $\mathbf{1}$ in the same range of concentrations $(8-16 \mu \mathrm{g} / \mathrm{mL})$. The indole derivative 12e proved to be the best compound of the series, with an increased activity against both H37Rv and CF73 strains (2.9 and $1 \mu \mathrm{g} / \mathrm{mL}$, respectively, in comparison to 10 and $8 \mu \mathrm{g} / \mathrm{mL}$ found for $\mathbf{1})$. Moreover, 12e also showed a similar profile against MDR-CF104 (10 vs $11 \mu \mathrm{g} / \mathrm{mL})$ and a slightly improved activity against MDR-CF81 (4 vs $10 \mu \mathrm{g} / \mathrm{mL}$ ). These data suggest that the presence of a secondary amine on the piperidine side chains could be beneficial for the anti-tubercular activity, as also observed in our previous work [27].

Finally, to prove the effectiveness of the most active compounds, their cytotoxicity was evaluated on MRC-5 and J774 cells. As a result, 12e showed a selectivity index 15 fold higher than that of TZ on MRC-5 cells (Table 3). In addition, 12e showed also a good selectivity toward the J774 macrophage cells.

Finally, the effect of $\mathrm{TZ}$ derivatives on the efflux pumps of the model surrogate organism $M$. smegmatis was tested in order to understand the mode of action of the new compounds. Efflux pump inhibition (EPI) is determined using a whole-cell-based assay which interrogates the total activity of the diverse sets of efflux pumps present in the cell. The EPI assay showed that some TZ derivatives are endowed with a good efflux pump inhibitory activity. However, there is a weak correlation between inhibition of bacterial growth and efflux pump inhibtion. The compounds 12b and 12e which showed the most promising antimycobacterial activity proved to be poor efflux pump inhibitors (Fig. 2). These 
Table 2

Activity of TZ derivatives on mycobacterium species (expressed as $\mu \mathrm{g} / \mathrm{mL}$ ).

\begin{tabular}{|c|c|c|c|c|c|c|c|}
\hline \multirow[t]{2}{*}{ Cmpd } & \multirow[t]{2}{*}{ M. smegmatis $\mathrm{mc}^{2} 155$} & \multirow[t]{2}{*}{ M. bovis BCG } & \multicolumn{3}{|c|}{ M. tuberculosis } & \multicolumn{2}{|c|}{ MDR-TB } \\
\hline & & & $\mathrm{mc}^{2} 7000$ & H37Rv & Susc. (CF73) & CF104 & CF81 \\
\hline TZ 1 & 16 & 16 & 8 & 10 & 8 & 11 & 10 \\
\hline 3 & 16 & 8 & 8 & 100 & $>100$ & $>100$ & $>100$ \\
\hline $4 \mathbf{a}$ & 16 & 8 & 8 & $>100$ & 37 & 32 & 44 \\
\hline $4 b$ & $>64$ & 64 & 64 & 45 & - & - & - \\
\hline 4c & $>64$ & $>64$ & $>64$ & - & - & - & - \\
\hline $7 \mathbf{a}$ & 64 & 64 & 27 & 100 & $>100$ & $>100$ & $>100$ \\
\hline 7b & $>64$ & $>64$ & $>64$ & - & - & - & - \\
\hline 7c & 32 & 8 & 27 & 69 & 27 & 23 & 33 \\
\hline 7d & $>64$ & $>64$ & $>64$ & - & - & - & - \\
\hline $7 e$ & $>64$ & $>64$ & $>64$ & - & - & - & - \\
\hline $7 f$ & 64 & 64 & 64 & - & - & - & - \\
\hline $7 \mathrm{~g}$ & 4 & $>64$ & $>64$ & 43 & 98 & 20 & 48 \\
\hline 7h & $>64$ & $>64$ & $>64$ & - & - & - & - \\
\hline $7 \mathbf{i}$ & $>64$ & $>64$ & $>64$ & - & - & - & - \\
\hline 9a & $>64$ & $>64$ & $>64$ & - & - & - & - \\
\hline 9b & - & - & - & $>100$ & $>100$ & 72 & $>100$ \\
\hline $12 a$ & $>64$ & $>64$ & $>64$ & $>64$ & 47 & $>64$ & 58 \\
\hline $12 b$ & 16 & 5.3 & 4 & 26 & 11 & 19 & 11 \\
\hline $12 c$ & $>64$ & $>64$ & $>64$ & - & - & - & - \\
\hline $12 d$ & $>64$ & $>64$ & $>64$ & 100 & $>100$ & $>100$ & $>100$ \\
\hline $12 e$ & 1.6 & 64 & - & 2.9 & 1 & 10 & 4 \\
\hline $13 a$ & 32 & 64 & 16 & $>64$ & 47 & $>64$ & 58 \\
\hline 13b & 16 & 8 & 8 & 19 & 16 & 16 & 12 \\
\hline $13 c$ & $>64$ & $>64$ & 64 & 60 & 39 & 48 & 46 \\
\hline 13d & $>64$ & $>64$ & $>64$ & - & - & - & - \\
\hline 16 & $>64$ & $>64$ & $>64$ & - & - & - & - \\
\hline INH & 4 & 0.063 & 0.125 & 0.03 & 0.03 & $>25$ & $>25$ \\
\hline RIF & - & - & 0.25 & 0.3 & 8 & $>25$ & $>25$ \\
\hline
\end{tabular}

Table 3

Cytotoxicity of compounds $\mathbf{1}, \mathbf{1 2} \mathbf{b}, \mathbf{1 2} \mathbf{e}, \mathbf{1 3 b}$ expressed as $\mu \mathrm{g} / \mathrm{mL}$ and Selectivity Index expressed as absolute number.

\begin{tabular}{llll}
\hline Cmpds & IC $_{50}$ MRC-5 & IC $_{50} \mathrm{J774}$ & SI $^{\mathrm{a}}$ \\
\hline TZ 1 & $8.2 \mu \mathrm{g} / \mathrm{mL}$ & $4.1 \mu \mathrm{g} / \mathrm{mL}$ & 1 \\
$\mathbf{1 2 b}$ & $10 \mu \mathrm{g} / \mathrm{mL}$ & $10.7 \mu \mathrm{g} / \mathrm{mL}$ & 0.9 \\
$\mathbf{1 2 e}$ & $15 \mu \mathrm{g} / \mathrm{mL}$ & $7.3 \mu \mathrm{g} / \mathrm{mL}$ & 15 \\
$\mathbf{1 3 b}$ & $13 \mu \mathrm{g} / \mathrm{mL}$ & $8.4 \mu \mathrm{g} / \mathrm{mL}$ & 0.8 \\
\hline
\end{tabular}

${ }^{a}$ Selectivity index is calculated as the ratio between the M. tuberculosis Susc. (CF73) MIC and the MRC-5 IC 50 . compounds could interfere with the cell-envelope permeability, as already hypothesized for 1 [23], by means other than inhibiting efflux pumps. On the other hand, the piperazine derivatives 7a and 7c which did not show antimycobacterial activity, were found to inhibit efflux pumps better than the reference chlorpromazine. This indicates that these compounds have the potential to reverse multidrug resistance and could be promising candidates for inclusion in a combination therapy regimen owing to synergistic combinations.

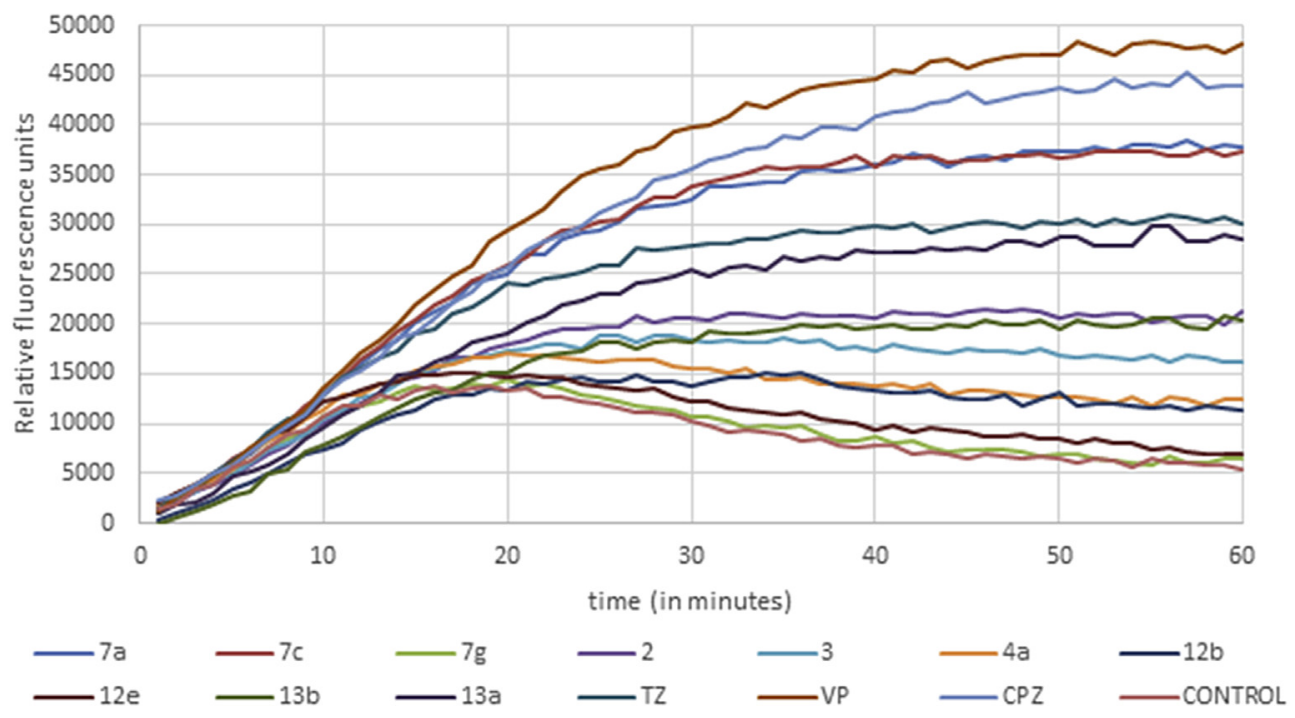

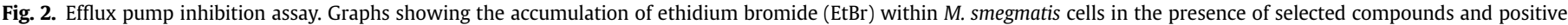

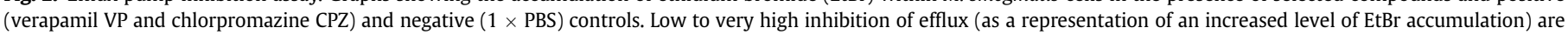
shown by relative fluorescent units. The experiments were performed in triplicate $(n=3)$, and the graph is plotted using the average values obtained. 


\section{Conclusions}

A classical medicinal chemistry approach has been applied to design and synthesise a narrow library of thioridazine derivatives by structural changes made on three different molecular portions. Antimycobacterial activity of the resulting compounds showed that the piperidine-ethyl side chain is required for inhibit nonpathogenic, pathogenic and MDR mycobacterial strains. Moreover, the SMe-phenothiazine scaffold of $\mathbf{1}$ could be only replaced with the $\mathrm{Cl}$-phenothiazine analogue or simplified into an indole moiety. The most active compound 12e, bearing a demethylated piperazine ring in addition to an indole heterocycle, showed an activity profile better than that of $\mathbf{1}$ and a cytotoxicity about 15-fold lower toward MRC-5 cells.

\section{Material and methods}

\subsection{Chemistry. Materials and methods}

${ }^{1} \mathrm{H}$ NMR and ${ }^{13} \mathrm{C}$ NMR spectra were recorded on JEOL Delta-270 or JEOL ECS-400 spectrometers operating at the frequencies indicated. Chemical shift $(\delta)$ are in ppm, referenced to tetramethylsilane. Coupling constants $(\mathrm{J})$ are reported in hertz and rounded to $0.5 \mathrm{~Hz}$. Splitting patterns are abbreviated as follows: singlet (s), doublet (d), triplet (t), quartet (q), multiplet (m), broad (br) or some combination of them. Infrared spectra were obtained using a Durascope diamond ATR system. Mass spectra (HRMS) were recorded at the EPSRC National Mass Spectrometry Service Centre on a Thermo Scientific LTQ Orbitrap XL mass spectrometer using low-resolution ESI or high-resolution nano ESI techniques. The purity of the compounds was assessed by reverse-phase liquid chromatography coupled with a mass spectrometer (Agilent series $1100 \mathrm{LC} / \mathrm{MSD}$ ) with a UV detector at $\mathrm{k}=254 \mathrm{~nm}$ and an electrospray ionization source (ESI). HPLC analyses were performed at $0.4 \mathrm{~mL} /$ min flow rate and using a binary solvent system of 95:5 methyl alcohol/water. All the solvents were of HPLC grade. Mass spectra were acquired in positive mode scanning over the mass range of 50-1500. The following ion source parameters were used: drying gas flow, $9 \mathrm{~mL} / \mathrm{min}$; nebulize pressure, $40 \mathrm{psig}$; and drying gas temperature, $350{ }^{\circ} \mathrm{C}$. All target compounds possess a purity of $\geq 95 \%$, as verified by HPLC analyses. TLC was performed using commercially available precoated plates and visualized with UV light at $254 \mathrm{~nm} ; \mathrm{KMnO}_{4}$ was used to reveal the products. Flash column chromatography was carried out using Fluorochem Davisil 40-63 $\mu \mathrm{m}, 60 \AA$ A. All reactions were conducted under a nitrogen atmosphere in oven-dried glassware unless stated otherwise. THF was distilled under nitrogen from sodium using a benzophenone indicator. Dichloromethane was purchased from Aldrich. All other solvents and commercially available reagents were used as received.

4.1.1. Synthesis of 1-chloroethyl 2-(2-(2-(methylthio)-10hphenothiazin-10-yl)ethyl)piperidine-1-carboxylate (2)

Thioridazine hydrochloride (1) $(3.87 \mathrm{mmol}, 1.57 \mathrm{~g}, 1$ eq.) was dissolved in a round bottomed flask containing dry DCE $(20 \mathrm{~mL})$ and $\mathrm{Et}_{3} \mathrm{~N}$ (7.74 mmol, $1 \mathrm{~mL}, 2$ eq.). The mixture was stirred at r.t. for $20 \mathrm{~min}$ before that 1-chloroethyl chloroformate $(7.74 \mathrm{mmol}$, $0.38 \mathrm{~mL}, 2$ eq.) was added to the solution. The mixture was left under $\mathrm{N}_{2}$ atmosphere at reflux for $12 \mathrm{~h}$. Then, the reaction mixture was quenched with $10 \mathrm{~mL}$ of water and extracted twice with $20 \mathrm{~mL}$ of EtOAc. The combined organic layers were washed with brine, dried over $\mathrm{Na}_{2} \mathrm{SO}_{4}$ and concentrated under reduced pressure giving a yellow-brown crude oil. The crude product was purified by chromatography on silica gel, using hexane/EtOAc (4:1) as eluent.

Yield: $84 \%$ (1.86 g). ${ }^{\mathbf{1}} \mathbf{H}$ NMR $\left(400 \mathrm{MHz} \mathrm{CDCl}_{3}\right) \delta 7.13-7.01(\mathrm{~m}$,
$2 \mathrm{H}), 7.01-6.90(\mathrm{~m}, 1 \mathrm{H}), 6.89-6.60(\mathrm{~m}, 4 \mathrm{H}), 6.59-6.29(\mathrm{~m}, 1 \mathrm{H})$, $4.20-3.90(\mathrm{~m}, 1 \mathrm{H}), 3.90-3.60(\mathrm{~m}, 2 \mathrm{H}), 2.90-2.74(\mathrm{~m}, 1 \mathrm{H}), 2.74-2.57$ $(\mathrm{m}, 1 \mathrm{H}), 2.36(\mathrm{~s}, 3 \mathrm{H}), 2.25-2.04(\mathrm{~m}, 1 \mathrm{H}), 1.77-1.60(\mathrm{~m}, 3 \mathrm{H})$, $1.58-1.16(\mathrm{~m}, 7 \mathrm{H}) \mathrm{ppm} .{ }^{13} \mathrm{C}$ NMR $\left(100 \mathrm{MHz} \mathrm{CDCl}_{3}\right) \delta 152.9,145.0$, 137.9, 127.8, 127.7, 127.4, 122.8, 121.0, 114.5, 83.4, 49.9, 44.5, 39.8, 29.1, 27.8, 25.4, 19.1, 16.5, $14.3 \mathrm{ppm}$. LRMS $\mathrm{m} / \mathrm{z}(\mathrm{ES}+) \mathrm{m} / \mathrm{z}: 463$ $[\mathrm{M}+\mathrm{H}]^{+}$

\subsubsection{Synthesis of 2-(methylthio)-10-(2-(piperidin-2-yl)ethyl)-10h- phenothiazine (3)}

Derivative 2 ( $3.84 \mathrm{mmol}, 1.7 \mathrm{~g}, 1$ eq.) was dissolved in $\mathrm{MeOH}$ $(20 \mathrm{~mL})$ and the solution was stirred at reflux for $12 \mathrm{~h}$ then the reaction mixture was concentrated by reduced pressure evaporation. Then, the reaction mixture was quenched with $20 \mathrm{~mL}$ of water and extracted twice with $20 \mathrm{~mL}$ of EtOAc. The combined organic layers were washed with brine, dried over $\mathrm{Na}_{2} \mathrm{SO}_{4}$ and concentrated under reduced pressure giving a yellow-brown crude oil. The obtained product $\mathbf{3}$ was purified by chromatography on silica gel, using EtOAc/ $\mathrm{MeOH} / \mathrm{Et}_{3} \mathrm{~N}$ (3.9:1:0.1) as eluent.

Yield: $85 \%$ (1.1 g). ${ }^{\mathbf{1}} \mathbf{H}$ NMR $\left(400 \mathrm{MHz} \mathrm{CDCl}_{3}\right) \delta 9.25$ (br. s., $\left.1 \mathrm{H}\right)$, $7.20-7.08(\mathrm{~m}, 2 \mathrm{H}), 7.03(\mathrm{~d}, J=6.9 \mathrm{~Hz}, 1 \mathrm{H}), 6.90(\mathrm{~d}, J=7.3 \mathrm{~Hz}, 2 \mathrm{H})$, $6.82(\mathrm{~m}, 2 \mathrm{H}), 4.13-3.93(\mathrm{~m}, 2 \mathrm{H}), 3.29(\mathrm{~d}, J=12.8 \mathrm{~Hz}, 1 \mathrm{H}), 3.02(\mathrm{~m}$, $1 \mathrm{H}), 2.68(\mathrm{t}, J=12.1 \mathrm{~Hz}, 1 \mathrm{H}), 2.46(\mathrm{~s}, 3 \mathrm{H}), 2.18-2.05(\mathrm{~m}, 1 \mathrm{H})$, 1.90-1.75 (m, 3H), 1.75-1.53 (m, 3H), 1.44-1.28 (m, 1H) ppm. ${ }^{13} \mathrm{C}$ NMR $\left(100 \mathrm{MHz} \mathrm{CDCl}_{3}\right) \delta 145.9,144.4,138.3,127.8,127.7,127.7,125.9$, 123.2, 122.5, 121.2, 116.3, 114.5, 55.7, 44.7, 43.7, 30.7, 28.8, 22.5, 22.2, 16.4 ppm. LRMS $m / z(\mathrm{ES}+) m / z: 357[\mathrm{M}+\mathrm{H}]^{+}$

\subsubsection{General procedure for the synthesis of thioridazine derivatives (4a-c)}

The 2-(methylthio)-10-(2-(piperidin-2-yl)ethyl)-10H-phenothiazine 3 ( $0.14 \mathrm{mmol}, 50 \mathrm{mg}, 1$ eq.) was added to a round bottomed flask containing a solution of the appropriate aldehyde/ketone $(0.21 \mathrm{mmol}, 1.5$ eq. $)$ in THF $(5 \mathrm{~mL})$. The solution was then allowed to stir at room temperature for $30 \mathrm{~min}$. Then, $\mathrm{NaBH}(\mathrm{AcO})_{3}(0.28 \mathrm{mmol}$, $60 \mathrm{mg}, 2$ eq.) was added and the reaction was allowed to react for $24 \mathrm{~h}$ at r.t. The reaction was quenched with $(20 \mathrm{~mL}) \mathrm{NaOH} 1 \mathrm{~N}$ solution and the resulting mixture was allowed to stir for $20 \mathrm{~min}$. Then the organic solvent was removed under reduced pressure evaporation. The residue was added with EtOAc and extracted $(3 \times 10 \mathrm{~mL})$ and finally dried over anhydrous $\mathrm{MgSO}_{4}$. The crude products $4 \mathbf{a}-\mathbf{c}$ were purified by chromatography on silica gel, using $\mathrm{EtOAc} / \mathrm{MeOH} / \mathrm{Et}_{3} \mathrm{~N}$ (3.9:1:0.1) as eluent.

4.1.3.1. 10-(2-(1-Benzylpiperidin-2-yl)ethyl)-2-(methylthio)-10Hphenothiazine (4a). Yield: $67 \%(42 \mathrm{mg}) .{ }^{\mathbf{1}} \mathbf{H}$ NMR $\left(400 \mathrm{MHz} \mathrm{CDCl}_{3}\right)$ $\delta 7.28-7.17(\mathrm{~m}, 5 \mathrm{H}) 7.14-7.10(\mathrm{~m}, 2 \mathrm{H}), 7.03(\mathrm{~d}, J=4.0 \mathrm{~Hz}, 1 \mathrm{H})$, 6.92-6.84 (m, 2H), $6.81(\mathrm{~d}, J=4.0 \mathrm{~Hz}, 2 \mathrm{H}), 3.97-3.83(\mathrm{~m}, 3 \mathrm{H}), 3.32$ $(\mathrm{d}, J=8.0 \mathrm{~Hz}, 1 \mathrm{H}), 2.75-2.70(\mathrm{~m}, 1 \mathrm{H}), 2.60-2.55(\mathrm{~m}, 1 \mathrm{H}), 2.43(\mathrm{~s}$, $3 \mathrm{H}), 2.14(\mathrm{~s}, 2 \mathrm{H}), 2.00-1.94(\mathrm{~m}, 1 \mathrm{H}), 1.77-1.41(\mathrm{~m}, 6 \mathrm{H}) \mathrm{ppm} .{ }^{13} \mathrm{C}$ NMR $\left(100 \mathrm{MHz} \mathrm{CDCl}_{3}\right) \delta$ 146.0, 145.1, 139.7, 137.6, 129.1, 128.8, 128.6, 128.3, 127.6, 127.6, 127.3, 126.8125.4, 122.6, 122.3, 120.9, 115.8, 114.7, 58.4, 57.7, 55.7, 50.6, 44.2, 29.6, 24.4, 23.1, 16.6 ppm. LRMS $m / z$ $(\mathrm{ES}+) \mathrm{m} / z: 447[\mathrm{M}+\mathrm{H}]^{+}$. HRMS (ESI) $m / z$ calcd. For $\mathrm{C}_{27} \mathrm{H}_{31} \mathrm{~N}_{2} \mathrm{~S}_{2}$ $[\mathrm{M}+\mathrm{H}]$ 447.1923, found 447.1913.

4.1.3.2. 2-(Methylthio)-10-(2-(1-propylpiperidin-2-yl)ethyl)-10Hphenothiazine (4b). Yield: $62 \%$ (34.5 $\mathrm{mg}) .{ }^{\mathbf{1}} \mathbf{H} \mathbf{~ N M R}\left(400 \mathrm{MHz}^{\mathrm{CDCl}} 3\right)$ $\delta 7.15-7.11(\mathrm{~m}, 2 \mathrm{H}), 7.03(\mathrm{~d}, J=4.0 \mathrm{~Hz}, 1 \mathrm{H}), 6.92-6.88(\mathrm{~m}, 2 \mathrm{H}), 6.80$ $(\mathrm{d}, J=4.0 \mathrm{~Hz}, 2 \mathrm{H}), 3.94-3.99(\mathrm{~m}, 1 \mathrm{H}), 3.83-3.79(\mathrm{~m}, 1 \mathrm{H}), 2.82-2.77$ $(\mathrm{m}, 1 \mathrm{H}), 2.51-2.48(\mathrm{~m}, 2 \mathrm{H}), 2.45(\mathrm{~s}, 3 \mathrm{H}), 2.33-2.22(\mathrm{~m}, 2 \mathrm{H})$, 2.16-2.06 (m, 1H), 1.85-1.56 (m, 4H), 1.43-1.29 (m, 5H), $0.75(\mathrm{t}$, $J=8.0 \mathrm{~Hz}, 3 \mathrm{H}) \mathrm{ppm} .{ }^{13} \mathrm{C} \mathrm{NMR}\left(100 \mathrm{MHz} \mathrm{CDCl}_{3}\right) \delta 145.8,145.0,137.6$, 127.6, 127.5, 127.3, 125.4, 122.6, 122.3, 120.9, 115.8, 114.7, 57.9, 55.7, 51.4, 44.4, 30.2, 27.9, 25.2, 23.3, 18.9, 16.6, $12.0 \mathrm{ppm}$. LRMS $\mathrm{m} / \mathrm{z}$ 
(ES+) $m / z: 399[\mathrm{M}+\mathrm{H}]^{+}$. HRMS (ESI) $m / z$ calcd. for $\mathrm{C}_{23} \mathrm{H}_{31} \mathrm{~N}_{2} \mathrm{~S}_{2}$ $[\mathrm{M}+\mathrm{H}]$ 399.1923, found 399.1916.

4.1.3.3. 10-(2-(1-isopropylpiperidin-2-yl)ethyl)-2-(methylthio)-10Hphenothiazine (4c). Yield: $68 \%(38 \mathrm{mg}){ }^{\mathbf{1}} \mathbf{H}$ NMR $\left(400 \mathrm{MHz} \mathrm{CDCl}_{3}\right)$ $\delta$ 7.15-7.11 (m, 2H), $7.03(\mathrm{~d}, J=4.0 \mathrm{~Hz}, 1 \mathrm{H}), 6.92-6.88(\mathrm{~m}, 2 \mathrm{H}), 6.80$ $(\mathrm{d}, J=4.0 \mathrm{~Hz}, 2 \mathrm{H}), 3.96-3.98(\mathrm{~m}, 1 \mathrm{H}), 3.83-3.79(\mathrm{~m}, 1 \mathrm{H}), 3.15(\mathrm{t}$, $J=8.0 \mathrm{~Hz}, 1 \mathrm{H}), 2.81-2.75(\mathrm{~m}, 1 \mathrm{H}), 2.62-2.59(\mathrm{~m}, 1 \mathrm{H}), 2.44(\mathrm{~s}, 3 \mathrm{H})$, $2.20-2.03(\mathrm{~m}, 2 \mathrm{H}), 1.85-1.24(\mathrm{~m}, 7 \mathrm{H}), 1.05(\mathrm{~d}, J=8.0 \mathrm{~Hz}, 3 \mathrm{H}), 0.77$ $(\mathrm{d}, J=8.0 \mathrm{~Hz}, 3 \mathrm{H}) \mathrm{ppm} .{ }^{13} \mathrm{C}$ NMR $\left(100 \mathrm{MHz} \mathrm{CDCl}_{3}\right) \delta 145.8,127.6$, $127.5,127.3,122.6,120.9,115.7,114.7,56.1,44.1,43.9,31.0,28.5,26.0$ 24.0, 21.8, 16.6, 13.9 ppm. LRMS $m / z(\mathrm{ES}+) \mathrm{m} / z$ : 399 [M+H] ${ }^{+}$. HRMS (ESI) $m / z$ calcd. for $\mathrm{C}_{23} \mathrm{H}_{31} \mathrm{~N}_{2} \mathrm{~S}_{2}[\mathrm{M}+\mathrm{H}]$ 399.1923, found 399.1916 .

\subsubsection{General procedure for the synthesis of compound (6a-c)}

The appropriate 2 -substituted phenothiazine $5 \mathbf{a}-\mathbf{c}(0.42 \mathrm{mmol}$, 1eq.) was added to $5 \mathrm{~mL}$ of DMF in a double neck round bottomed flask. NaH (0.46 mmol, $11 \mathrm{mg}, 1.1$ eq.) was added to the stirring solution at $0{ }^{\circ} \mathrm{C}$, and the mixture was allowed to reach r.t stirring for $20 \mathrm{~min}$. Then, 1-bromo-3-chloropropane $(0.46 \mathrm{mmol}, 45 \mu \mathrm{L} 1.1 \mathrm{eq})$ was added to the stirring solution. The reaction mixture was allowed to stir under $\mathrm{N}_{2}$ atmosphere for $12 \mathrm{~h}$ at r.t. before being quenched with $10 \mathrm{~mL}$ of water and extracted twice with $20 \mathrm{~mL}$ of EtOAc. The combined organic layers were washed with brine $(10 \mathrm{~mL})$, dried over $\mathrm{Na}_{2} \mathrm{SO}_{4}$ and concentrated under reduced pressure giving a yellow-brown crude oil. The obtained product was purified by chromatography on silica gel, using hexane/EtOAc $(4: 1)$ as eluent.

4.1.4.1. 10-(3-Chloropropyl)-2-(methylthio)-10H-phenothiazine (6a). Yield: $93 \%(125 \mathrm{mg}) .{ }^{1} \mathbf{H}$ NMR $\left(400 \mathrm{MHz} \mathrm{CDCl}_{3}\right) \delta 7.18-7.14(\mathrm{~m}, 2 \mathrm{H})$, $7.06(\mathrm{~d}, J=8.0 \mathrm{~Hz}, 1 \mathrm{H}), 6.95-6.88(\mathrm{~m}, 2 \mathrm{H}), 6.84-6.81(\mathrm{~m}, 2 \mathrm{H}), 4.06$ $(\mathrm{t}, J=8.0 \mathrm{~Hz}, 2 \mathrm{H}), 3.65(\mathrm{t}, J=8.0 \mathrm{~Hz}, 2 \mathrm{H}), 2.46(\mathrm{~s}, 3 \mathrm{H}), 2.22(\mathrm{t}$, $J=8.0 \mathrm{~Hz}, 2 \mathrm{H}) \mathrm{ppm} .{ }^{13} \mathrm{C}$ NMR $\left(100 \mathrm{MHz} \mathrm{CDCl}_{3}\right) \delta 145.6,145.9,137.8$, $127.8,127.7,127.5,125.8,123.0,122.7,121.1,115.9,114.6,44.1,42.5$, 29.7, $16.5 \mathrm{ppm}$. LRMS $\mathrm{m} / \mathrm{z}(\mathrm{ES}+) \mathrm{m} / \mathrm{z}: 322[\mathrm{M}+\mathrm{H}]^{+}$.

4.1.4.2. 2-Chloro-10-(3-chloropropyl)-10H-phenothiazine (6b). Yield: $84 \%(109 \mathrm{mg}) .{ }^{\mathbf{1}} \mathbf{H}$ NMR $\left(400 \mathrm{MHz} \mathrm{CDCl}_{3}\right) \delta 7.19-7.14(\mathrm{~m}, 2 \mathrm{H})$ $7.04(\mathrm{~d}, J=8.0 \mathrm{~Hz}, 1 \mathrm{H}), 6.95(\mathrm{t}, J=8.0 \mathrm{~Hz}, 1 \mathrm{H}), 6.91-6.88(\mathrm{~m}, 2 \mathrm{H})$, $6.86(\mathrm{~s}, 1 \mathrm{H}), 4.04(\mathrm{t}, J=8.0 \mathrm{~Hz}, 2 \mathrm{H}), 3.65(\mathrm{t}, J=8.0 \mathrm{~Hz}, 2 \mathrm{H}), 2.25-2.18$ $(\mathrm{m}, 2 \mathrm{H}) \mathrm{ppm} .{ }^{13} \mathrm{C} \mathrm{NMR}(100 \mathrm{MHz} \mathrm{CDCl}) \delta 146.5,144.4,133.4,128.2$, $127.8,127.6,125.5,124.2,123.3,122.7,116.0,115.9,44.1,42.3$, $29.5 \mathrm{ppm}$. LRMS $\mathrm{m} / \mathrm{z}(\mathrm{ES}+) \mathrm{m} / \mathrm{z}: 332[\mathrm{M}+\mathrm{Na}]^{+}$

4.1.4.3. 10-(3-Chloropropyl)-10H-phenothiazine (6c). Yield: $82 \%$ (94 mg). ${ }^{1}$ H NMR (400 MHz CDCl 3 ) $\delta$ 7.19-7.15 (m, 4H), 6.96-6.89 $(\mathrm{m}, 4 \mathrm{H}), 4.07(\mathrm{t}, J=8.0 \mathrm{~Hz}, 2 \mathrm{H}), 3.66(\mathrm{t}, J=8.0 \mathrm{~Hz}, 2 \mathrm{H}), 2.23(\mathrm{t}$, $J=8.0 \mathrm{~Hz}, 2 \mathrm{H}) \mathrm{ppm} .{ }^{13} \mathrm{C}$ NMR $\left(100 \mathrm{MHz} \mathrm{CDCl}_{3}\right) \delta 145.2,127.8,127.4$, 125.8, 122.9, 115.7, 44.0, 42.6, 29.7 ppm. LRMS $m / z(E S+) ~ m / z: 276$ $[\mathrm{M}+\mathrm{H}]^{+}$

\subsubsection{General procedure for the synthesis of thioridazine derivatives} (7a-i)

The appropriate chloro-derivative $\mathbf{6 a}-\mathbf{c}(0.18 \mathrm{mmol}, 1$ eq. $)$ was dissolved in a round bottomed flask containing dry DMF $(10 \mathrm{~mL})$ and $\mathrm{Et}\left({ }_{\mathrm{i}} \mathrm{Pr}\right)_{2} \mathrm{~N}$ (DIPEA, $0.19 \mathrm{mmol}, 1.1$ eq.). The appropriate amine ( $\mathrm{N}-$ substituted piperazine or thiomorpholine) $(0.72 \mathrm{mmol}, 4$ eq.) was then added to the solution followed by $\mathrm{NaI}(0.036 \mathrm{mmol}, 5 \mathrm{mg}, 0.2$ eq.). The mixture was left under $\mathrm{N}_{2}$ atmosphere at $150{ }^{\circ} \mathrm{C}$ for $3 \mathrm{~h}$, after which time it was added with water $(10 \mathrm{~mL})$ and extracted twice with EtOAc $(20 \mathrm{~mL})$. The combined organic layers were washed with brine, dried over $\mathrm{Na}_{2} \mathrm{SO}_{4}$ and concentrated under reduced pressure. The obtained product was purified by chromatography on silica gel, using EtOAc/MeOH/Et ${ }_{3} \mathrm{~N}$ (3.9:1:0.1) as eluent.
4.1.5.1. 10-(3-(4-Methylpiperazin-1-yl)propyl)-10H-phenothiazine (7a): [28].. Yield: 99\% (60 mg). ${ }^{\mathbf{1}} \mathbf{H}$ NMR (400 MHz CDCl 3$) \delta 7.12(\mathrm{t}$, $J=8.0 \mathrm{~Hz}, 4 \mathrm{H}), 6.90(\mathrm{t}, J=8.0 \mathrm{~Hz}, 4 \mathrm{H}), 3.90(\mathrm{t}, J=8.0 \mathrm{~Hz}, 2 \mathrm{H}), 2.46(\mathrm{t}$, $J=8.0 \mathrm{~Hz}, 2 \mathrm{H}), 2.42-2.34(\mathrm{~m}, 8 \mathrm{H}), 2.26(\mathrm{~s}, 3 \mathrm{H}), 1.94(\mathrm{~d}, J=8.0 \mathrm{~Hz}$, $2 \mathrm{H}) \mathrm{ppm} .{ }^{13} \mathrm{C}$ NMR $\left(100 \mathrm{MHz} \mathrm{CDCl}_{3}\right) \delta 145.2,127.5,127.3,125.1$, 122.5, 115.6, 55.7, 55.1, 53.2, 46.0, 45.4, 24.5 ppm. LRMS $m / z$ (ES+) $\mathrm{m} / z: 340[\mathrm{M}+\mathrm{H}]^{+}$.

4.1.5.2. 10-(3-(4-Phenylpiperazin-1-yl)propyl)-10H-phenothiazine (7b). Yield: $62 \%(44 \mathrm{mg}){ }^{\mathbf{1}} \mathbf{H}$ NMR $\left(400 \mathrm{MHz} \mathrm{CDCl}_{3}\right) \delta 7.25(\mathrm{t}$, $J=8.0 \mathrm{~Hz}, 2 \mathrm{H}), 7.13(\mathrm{~d}, J=8.0 \mathrm{~Hz}, 4 \mathrm{H}), 6.92-6.88(\mathrm{~m}, 6 \mathrm{H}), 6.84(\mathrm{t}$, $J=8.0 \mathrm{~Hz}, 1 \mathrm{H}), 3.95(\mathrm{t}, J=8.0 \mathrm{~Hz}, 2 \mathrm{H}), 3.14(\mathrm{t}, J=8.0 \mathrm{~Hz}, 4 \mathrm{H}), 2.57(\mathrm{t}$, $J=8.0 \mathrm{~Hz}, 4 \mathrm{H}), 2.53(\mathrm{t}, J=8.0 \mathrm{~Hz}, 2 \mathrm{H}), 2.02-1.95(\mathrm{~m}, 2 \mathrm{H}) \mathrm{ppm} .{ }^{13} \mathrm{C}$ $\operatorname{NMR}\left(100 \mathrm{MHz} \mathrm{CDCl}_{3}\right) \delta 151.4,145.3,129.2,127.5,127.3,125.2,122.5$, 119.7, 116.1, 115.6, 55.7, 53.4, 49.2, 45.3, 24.4 ppm. LRMS m/z (ES+) $m / z: 402[\mathrm{M}+\mathrm{H}]^{+}$. HRMS (ESI) $m / z$ calcd. for $\mathrm{C}_{25} \mathrm{H}_{28} \mathrm{~N}_{3} \mathrm{~S}[\mathrm{M}+\mathrm{H}]$ 402.1998, found 402.1995 .

4.1.5.3. 10-(3-(4-Methylpiperazin-1-yl)propyl)-2-(methylthio)-10Hphenothiazine (7c). Yield: $99 \%$ (68 $\mathrm{mg}) .{ }^{\mathbf{1}} \mathbf{H}$ NMR (400 $\left.\mathrm{MHz} \mathrm{CDCl}_{3}\right)$ $\delta$ 7.11-7.09 (m, 2H), $7.01(\mathrm{~d}, J=8.0 \mathrm{~Hz}, 1 \mathrm{H}), 6.90-6.85(\mathrm{~m}, 2 \mathrm{H})$, 6.80-6.77 (m, 2H), $3.89(\mathrm{t}, J=8.0 \mathrm{~Hz}, 2 \mathrm{H}), 2.50-2.33(\mathrm{~m}, 8 \mathrm{H}), 2.46$ $(\mathrm{t}, J=8.0 \mathrm{~Hz}, 2 \mathrm{H}), 2.44(\mathrm{~s}, 3 \mathrm{H}), 2.26(\mathrm{~s}, 3 \mathrm{H}), 1.94-1.92(\mathrm{~m}, 2 \mathrm{H}) \mathrm{ppm}$. ${ }^{13}$ C NMR $\left(100 \mathrm{MHz} \mathrm{CDCl}_{3}\right) \delta 145.2,144.9,137.5,127.6,127.5,127.3$, 125.2, 122.6, 122.2, 120.8, 115.8, 114.7, 55.6, 55.1, 53.2, 46.0, 45.3, 24.4, 16.6 ppm. LRMS $m / z(E S+) m / z: 386[\mathrm{M}+\mathrm{H}]^{+}$. HRMS (ESI) $m / z$ calcd. for $\mathrm{C}_{21} \mathrm{H}_{28} \mathrm{~N}_{3} \mathrm{~S}_{2}[\mathrm{M}+\mathrm{H}] 386.1719$, found 386.1739 .

4.1.5.4. 2-(Methylthio)-10-(3-(4-phenylpiperazin-1-yl)propyl)-10Hphenothiazine (7d). Yield: $77 \%$ (62 mg). ${ }^{\mathbf{1}} \mathbf{H}$ NMR (400 $\left.\mathrm{MHz} \mathrm{CDCl}_{3}\right)$ $\delta 7.24(\mathrm{t}, J=8.0 \mathrm{~Hz}, 2 \mathrm{H}), 7.12(\mathrm{~d}, J=8.0 \mathrm{~Hz}, 2 \mathrm{H}), 7.03(\mathrm{~d}, J=8.0 \mathrm{~Hz}$, $1 \mathrm{H}), 6.92-6.88(\mathrm{~m}, 4 \mathrm{H}), 6.85-6.80(\mathrm{~m}, 3 \mathrm{H}), 3.94(\mathrm{t}, J=8.0 \mathrm{~Hz}, 2 \mathrm{H})$, $3.14(\mathrm{t}, J=8.0 \mathrm{~Hz}, 4 \mathrm{H}), 2.56(\mathrm{t}, J=8.0 \mathrm{~Hz}, 4 \mathrm{H}), 2.51(\mathrm{t}, J=8.0 \mathrm{~Hz}, 2 \mathrm{H})$, $2.45(\mathrm{~s}, 3 \mathrm{H}), 1.99-1.96(\mathrm{~m}, 2 \mathrm{H}) \mathrm{ppm} .{ }^{13} \mathrm{C}$ NMR $\left(100 \mathrm{MHz} \mathrm{CDCl}_{3}\right)$ $\delta$ 151.4, 145.7, 145.02, 137.6, 129.2, 127.6, 127.5, 127.3, 125.3, 122.7, 122.3, 120.9, 119.7, 116.1, 115.8, 114.8, 55.7, 53.4, 49.2, 45.3, 24.4, $16.6 \mathrm{ppm}$. LRMS $m / z(\mathrm{ES}+) \mathrm{m} / z: 448[\mathrm{M}+\mathrm{H}]^{+}$. HRMS (ESI) $\mathrm{m} / z$ calcd. for $\mathrm{C}_{26} \mathrm{H}_{30} \mathrm{~N}_{3} \mathrm{~S}_{2}[\mathrm{M}+\mathrm{H}]$ 448.1876, found 448.1866 .

4.1.5.5. 2-(Methylthio)-10-(3-thiomorpholinopropyl)-10H-phenothiazine (7e). Yield: 99\% (69 mg). ${ }^{\mathbf{1}} \mathbf{H}$ NMR (400 $\mathrm{MHz}^{\mathrm{CDCl}} 3$ ) $\delta$ 7.14-7.03 (m, 2H), $7.01(\mathrm{~d}, J=8.0 \mathrm{~Hz}, 1 \mathrm{H}), 6.91-6.86(\mathrm{~m}, 2 \mathrm{H})$, $6.80-6.77(\mathrm{~m}, 2 \mathrm{H}), 3.90(\mathrm{t}, J=8.0 \mathrm{~Hz}, 2 \mathrm{H}), 2.63-2.57(\mathrm{~m}, 8 \mathrm{H}), 2.45$ $(\mathrm{s}, 3 \mathrm{H}), 1.89(\mathrm{t}, J=8.0 \mathrm{~Hz}, 2 \mathrm{H}) 1.34-1.22(\mathrm{~m}, 2 \mathrm{H}) \mathrm{ppm} .{ }^{13} \mathrm{C}$ NMR $\left(100 \mathrm{MHz} \mathrm{CDCl}_{3}\right) \delta 145.7,144.9,137.6,127.6,127.5,127.3,122.6$, 122.2, 120.8, 115.9, 114.8, 56.1, 55.2, 45.1, 28.1, 24.1, 16.6 ppm. LRMS $m / z($ ES +$) m / z: 389[\mathrm{M}+\mathrm{H}]^{+}$. HRMS (ESI) $m / z$ calcd. for $\mathrm{C}_{20} \mathrm{H}_{25} \mathrm{~N}_{2} \mathrm{~S}_{3}$ $[\mathrm{M}+\mathrm{H}]$ 389.1174, found 389.1172.

4.1.5.6. 10-(3-(4-Adamantan-1-yl)piperazin-1-yl)propyl)-2-(methylthio)-10H-phenothiazine (7f). Yield: $71 \% \quad(64 \quad \mathrm{mg}) .{ }^{1} \mathbf{H}$ NMR $\left(400 \mathrm{MHz} \mathrm{CDCl}_{3}\right) \delta 7.17-7.07(\mathrm{~m}, 2 \mathrm{H}), 7.02(\mathrm{~d}, J=7.8 \mathrm{~Hz}, 1 \mathrm{H})$, 6.92-6.85 (m, 2H), 6.84-6.76 (m, 2H), $3.89(\mathrm{t}, J=6.9 \mathrm{~Hz}, 2 \mathrm{H})$, 2.56-2.26 (m, 12H), 2.07-1.88 ( $\mathrm{m}, 8 \mathrm{H}), 1.88-1.74(\mathrm{~m}, 4 \mathrm{H}), 1.71-1.53$ $(\mathrm{m}, 4 \mathrm{H}), 1.35$ (d, $J=11.9 \mathrm{~Hz}, 2 \mathrm{H}) \mathrm{ppm} .{ }^{13} \mathrm{C}$ NMR $\left(100 \mathrm{MHz} \mathrm{CDCl}_{3}\right)$ $\delta$ 145.8, 144.9, 137.6, 127.6, 127.5, 127.3, 125.3, 122.7, 122.3, 120.8, 115.9, 114.7, 55.4, 54.3, 53.2, 46.7, 45.4, 45.2, 44.0, 43.9, 41.0, 38.7, 38.0, 36.8, 36.7, 29.7, 24.3, $16.6 \mathrm{ppm}$. LRMS $\mathrm{m} / \mathrm{z}(\mathrm{ES}+) \mathrm{m} / \mathrm{z}: 506$ $[\mathrm{M}+\mathrm{H}]^{+}$. HRMS (ESI) $\mathrm{m} / z$ calcd. for $\mathrm{C}_{30} \mathrm{H}_{40} \mathrm{~N}_{3} \mathrm{~S}_{2}[\mathrm{M}+\mathrm{H}]$ 506.2658, found 506.2644 .

4.1.5.7. 10-(3-(4-(Adamantan-2-yl)piperazin-1-yl)propyl)-2-(methylthio)-10H-phenothiazine (7g). Yield: $72 \%$ (65 mg). ${ }^{\mathbf{1}} \mathbf{H}$ NMR $\left(400 \mathrm{MHz} \mathrm{CDCl}_{3}\right) \delta 7.15-7.04(\mathrm{~m}, 2 \mathrm{H}), 7.01(\mathrm{~d}, J=7.8 \mathrm{~Hz}, 1 \mathrm{H})$, $6.92-6.81(\mathrm{~m}, 2 \mathrm{H}), 6.81-6.73(\mathrm{~m}, 2 \mathrm{H}), 3.87(\mathrm{t}, J=6.6 \mathrm{~Hz}, 2 \mathrm{H})$, 
3.58-3.41 (m, 1H), 3.38-3.25 (m, 1H), $2.70(\mathrm{~s}, 3 \mathrm{H}), 2.64-2.59(\mathrm{~m}$, $2 \mathrm{H}), 2.59-2.55(\mathrm{~m}, 2 \mathrm{H}), 2.55-2.49(\mathrm{~m}, 2 \mathrm{H}), 2.49-2.44(\mathrm{~m}, 3 \mathrm{H}), 2.43$ (s, 3H), $2.07(\mathrm{~m}, 5 \mathrm{H}), 1.97-1.87(\mathrm{~m}, 2 \mathrm{H}), 1.73(\mathrm{~m}, 5 \mathrm{H}), 1.64(\mathrm{~d}$, $J=2.3 \mathrm{~Hz}, 3 \mathrm{H}) \mathrm{ppm}^{13}{ }^{13} \mathbf{C ~ N M R}\left(100 \mathrm{MHz} \mathrm{CDCl}_{3}\right) \delta 145.8,144.9,137.6$, 127.6, 127.5, 127.3, 125.2, 122.6, 122.2, 120.8, 115.8, 114.7, 67.8, 56.0, 54.0, 49.6, 45.6, 40.6, 37.9, 37.3, 31.4, 29.1, 28.9, 27.6, 27.4, 24.4, $16.6 \mathrm{ppm}$. LRMS $m / z(\mathrm{ES}+) \mathrm{m} / z: 506[\mathrm{M}+\mathrm{H}]^{+}$. HRMS (ESI) $\mathrm{m} / z$ calcd. for $\mathrm{C}_{30} \mathrm{H}_{40} \mathrm{~N}_{3} \mathrm{~S}_{2}[\mathrm{M}+\mathrm{H}]$ 506.2658, found 506.2648.

4.1.5.8. 2-Chloro-10-(3-(4-phenylpiperazin-1-yl)propyl)-10H-phenothiazine (7h). Yield: $57 \%$ (44 mg). ${ }^{\mathbf{1}} \mathbf{H}$ NMR (400 $\left.\mathrm{MHz} \mathrm{CDCl}_{3}\right) \delta 7.24$ $(\mathrm{t}, J=8.0 \mathrm{~Hz}, 2 \mathrm{H}), 7.17-7.11(\mathrm{~m}, 2 \mathrm{H}), 7.01(\mathrm{~d}, J=8.0 \mathrm{~Hz}, 1 \mathrm{H})$, 6.94-6.63 (m, 7H), $3.92(\mathrm{t}, J=8.0 \mathrm{~Hz}, 2 \mathrm{H}), 3.15(\mathrm{t}, J=8.0 \mathrm{~Hz}, 4 \mathrm{H})$, $2.57(\mathrm{t}, J=8.0 \mathrm{~Hz}, 4 \mathrm{H}), 2.51(\mathrm{t}, J=8.0 \mathrm{~Hz}, 2 \mathrm{H}), 2.00-1.96(\mathrm{~m}, 2 \mathrm{H})$ ppm. ${ }^{13} \mathrm{C}$ NMR $\left(100 \mathrm{MHz} \mathrm{CDCl}_{3}\right) \delta 151.4,146.6,144.6,133.3,129.2$, 128.0, 127.6, 127.5, 124.8, 123.6, 123.0, 122.3, 119.8, 116.1, 115.9, 55.6, 53.5, 49.2, 45.4, 24.3 ppm. LRMS $m / z(E S+) m / z: 436[\mathrm{M}+\mathrm{H}]^{+}$. HRMS (ESI) $m / z$ calcd. for $\mathrm{C}_{25} \mathrm{H}_{27} \mathrm{ClN}_{3} \mathrm{~S}[\mathrm{M}+\mathrm{H}] 436.1609$, found 436.1618 .

4.1.5.9. 2-Chloro-10-(3-thiomorpholinopropyl)-10H-phenothiazine (7i). Yield: $90 \%$ (61 mg). ${ }^{1} \mathbf{H}$ NMR $\left(400 \mathrm{MHz} \mathrm{CDCl}_{3}\right) \delta 7.15-7.08(\mathrm{~m}$, $2 \mathrm{H}), 6.99(\mathrm{~d}, J=8.0 \mathrm{~Hz}, 1 \mathrm{H}), 6.93-6.81(\mathrm{~m}, 4 \mathrm{H}), 3.88(\mathrm{t}, J=8.0 \mathrm{~Hz}$, $2 \mathrm{H}), 2.66-2.57(\mathrm{~m}, 8 \mathrm{H}), 2.45(\mathrm{t}, J=8.0 \mathrm{~Hz}, 2 \mathrm{H}), 1.91-1.85(\mathrm{~m}, 2 \mathrm{H})$ ppm. ${ }^{13} \mathrm{C} \mathrm{NMR}\left(100 \mathrm{MHz} \mathrm{CDCl}_{3}\right) \delta 146.5,144.6,133.2,127.9,127.6$, $127.5,124.8,123.5,122.9,122.3,115.9,56.0,55.8,45.1,28.1$, 24.0 ppm. LRMS $m / z(\mathrm{ES}+) \mathrm{m} / z: 377[\mathrm{M}+\mathrm{H}]^{+}$. HRMS (ESI) $\mathrm{m} / z$ calcd. for $\mathrm{C}_{19} \mathrm{H}_{22} \mathrm{ClN}_{2} \mathrm{~S}_{2}[\mathrm{M}+\mathrm{H}]$ 377.0907, found 377.0917.

\subsubsection{2-Chloro-1-(2-(methylthio)-10H-phenothiazin-10-yl) ethanone (8)}

The phenothiazine $\mathbf{5 a}$ ( $1.22 \mathrm{mmol}, 300 \mathrm{mg}, 1$ eq.) was dissolved to $15 \mathrm{~mL}$ of DMF in a double neck round bottomed flask. $\mathrm{NaH}$ (1.83 mmol, $44 \mathrm{mg}, 1.5$ eq.) was added to the stirring solution at $0{ }^{\circ} \mathrm{C}$, which then was allowed to reach r.t. under stirring for $20 \mathrm{~min}$. Then, 2-chloroacetyl chloride (3.66 mmol, $0.29 \mathrm{~mL}, 3$ eq.) was added and the reaction mixture was stirred under $\mathrm{N}_{2}$ atmosphere for $3 \mathrm{~h}$ at r.t. The reaction mixture was then quenched with water $(10 \mathrm{~mL})$ and extracted twice with EtOAc $(20 \mathrm{~mL})$. The combined organic layers were washed with brine, dried over $\mathrm{Na}_{2} \mathrm{SO}_{4}$ and concentrated under reduced pressure giving a yellow-brown crude oil. The obtained product was purified by chromatography on silica gel, using hexane/EtOAc (3:2) as eluent.

Yield: $58 \%$ (227 mg). ${ }^{1} \mathbf{H}$ NMR (400 $\left.\mathrm{MHz}^{\mathrm{CDCl}} 3\right) \delta 7.53(\mathrm{~d}$, $J=8.0 \mathrm{~Hz}, 1 \mathrm{H}), 7.47-7.43(\mathrm{~m}, 2 \mathrm{H}), 7.36-7.31(\mathrm{~m}, 2 \mathrm{H}), 7.27-7.23(\mathrm{~m}$, $1 \mathrm{H}), 7.14-7.11(\mathrm{~m}, 1 \mathrm{H}), 4.16(\mathrm{~d}, J=8.0 \mathrm{~Hz}, 2 \mathrm{H}), 2.49(\mathrm{~s}, 3 \mathrm{H}) \mathrm{ppm} .{ }^{13} \mathrm{C}$ NMR $\left(100 \mathrm{MHz} \mathrm{CDCl}_{3}\right) \delta 166.3,138.8,138.3,137.5,128.3,128.2,127.7$, 127.5, 126.5, 125.7, 124.1, 40.7, 15.9 ppm. LRMS $\mathrm{m} / z$ (ES+) $\mathrm{m} / \mathrm{z}: 322$ $[\mathrm{M}+\mathrm{H}]^{+}$.

\subsubsection{Synthesis of 2-(4-methylpiperazin-1-yl)-1-(2-(methylthio)- 10H-phenothiazin-10-yl)ethanone (9a)}

The 1-methylpiperazine $(0.63 \mathrm{mmol}, 0.07 \mathrm{~mL}, 4$ eq.) was dissolved in a round bottomed flask containing dry DMF $(5 \mathrm{~mL})$ and $\mathrm{Et}\left({ }_{\mathrm{i}} \mathrm{Pr}\right)_{2} \mathrm{~N}$ (DIPEA, $0.17 \mathrm{mmol}, 1.1$ eq.). The mixture was stirred at r.t for $20 \mathrm{~min}$ and then 2-chloro-1-(2-(methylthio)-10H-phenothiazin-10-yl)ethanone (8) $(0.15 \mathrm{mmol}, 48 \mathrm{mg}, 1$ eq.) was added to the solution followed by $\mathrm{NaI}(0.03 \mathrm{mmol}, 4.5 \mathrm{mg}, 0.2 \mathrm{eq}$.). The mixture was left under $\mathrm{N}_{2}$ atmosphere at $153{ }^{\circ} \mathrm{C}$ for $3 \mathrm{~h}$. Then, the reaction mixture was quenched with water $(10 \mathrm{~mL})$ and extracted twice with EtOAc $(20 \mathrm{~mL})$. The combined organic layers were washed with brine, dried over $\mathrm{Na}_{2} \mathrm{SO}_{4}$ and concentrated under reduced pressure giving a yellow-brown crude oil. The obtained product was purified by chromatography on silica gel, using EtOAc/MeOH/ $\mathrm{Et}_{3} \mathrm{~N}(3.9: 1: 0.1)$ as eluent.
Yield: 96\% (55 mg). ${ }^{\mathbf{1}} \mathbf{H}$ NMR (400 MHz $\left.\mathrm{CDCl}_{3}\right) \delta 7.51-7.47(\mathrm{~m}$, $2 \mathrm{H}), 7.41(\mathrm{~d}, J=8.0 \mathrm{~Hz}, 1 \mathrm{H}), 7.32-7.26(\mathrm{~m}, 2 \mathrm{H}), 7.22-7.18(\mathrm{~m}, 1 \mathrm{H})$, 7.10-7.08 (m, 1H), 3.30-3.31 (m, 2H), $2.47(\mathrm{~s}, 3 \mathrm{H}), 2.44-2.27(8 \mathrm{H})$, $2.22(\mathrm{~s}, 3 \mathrm{H}) \mathrm{ppm} .{ }^{13} \mathrm{C}$ NMR $\left(100 \mathrm{MHz} \mathrm{CDCl}_{3}\right) \delta 168.6,139.3,138.6$, 137.9, 128.0, 127.9, 127.0, 126.9, 125.1, 124.9, 60.4, 54.9, 52.9, 45.9, $16.2 \mathrm{ppm}$. LRMS $\mathrm{m} / \mathrm{z}(\mathrm{ES}+) \mathrm{m} / \mathrm{z}: 386[\mathrm{M}+\mathrm{H}]^{+}$. HRMS (ESI) $\mathrm{m} / z$ calcd. for $\mathrm{C}_{20} \mathrm{H}_{24} \mathrm{~N}_{3} \mathrm{~S}_{2} \mathrm{O}[\mathrm{M}+\mathrm{H}]$, 386.1355 found 386.1351 .

\subsubsection{Synthesis of 1-(2-(methylthio)-10H-phenothiazin-10-yl)-2- (piperidin-1-yl)ethanone (9b)}

Piperidine ( $1.22 \mathrm{mmol}, 0.12 \mathrm{~mL}, 4$ eq.) was added to a round bottomed flask containing DMF $(5 \mathrm{~mL})$ and $\mathrm{Et}\left({ }_{\mathrm{i}} \mathrm{Pr}\right)_{2} \mathrm{~N}$ (DIPEA, $0.31 \mathrm{mmol}, 1$ eq.) and the mixture was allowed to stir at room temperature for $30 \mathrm{~min}$ before 2-chloro-1-(2-(methylthio)-10Hphenothiazin-10-yl)ethanone (8) $(0.31 \mathrm{mmol}, 98 \mathrm{mg}, 1$ eq.) was added to the solution. The reaction was allowed to stir for $3 \mathrm{~h}$ at $150{ }^{\circ} \mathrm{C}$. The reaction mixture was then quenched with water $(10 \mathrm{~mL})$ and extracted twice with EtOAc $(20 \mathrm{~mL})$. The combined organic layers were washed with brine, dried over $\mathrm{Na}_{2} \mathrm{SO}_{4}$ and concentrated under reduced pressure giving a yellow-brown crude oil. The obtained product was purified by chromatography on silica gel, using EtOAc/MeOH/Et $3 \mathrm{~N}$ (3.9:1:0.1) as eluent.

Yield: $91 \%(104 \mathrm{mg}) .{ }^{1} \mathbf{H}$ NMR $\left(400 \mathrm{MHz} \mathrm{CDCl}_{3}\right) \delta 7.51-7.47(\mathrm{~m}$, $2 \mathrm{H}), 7.40(\mathrm{~d}, J=8.0 \mathrm{~Hz}, 1 \mathrm{H}), 7.30-7.24(\mathrm{~m}, 1 \mathrm{H}), 7.19(\mathrm{t}, J=8.0 \mathrm{~Hz}, 1 \mathrm{H})$, $7.08(\mathrm{~d}, J=12.0 \mathrm{~Hz}, 2 \mathrm{H}), 3.24-3.23(\mathrm{~d}, J=8.0 \mathrm{~Hz}, 2 \mathrm{H}), 2.47(\mathrm{~s}, 3 \mathrm{H})$, $2.35(\mathrm{~m}, 4 \mathrm{H}), 1.46-1.41(\mathrm{~m}, 4 \mathrm{H}), 1.32-1.29(\mathrm{~m}, 2 \mathrm{H}) \mathrm{ppm} .{ }^{13} \mathrm{C}$ NMR $\left(100 \mathrm{MHz} \mathrm{CDCl}_{3}\right) \delta 163.7,138.9,135.8,135.7,132.3,132.2,126.7$, 126.7, 122.2, 118.0, 116.2, 56.8, 56.1, 25.2, 24.2, 16.0 ppm. LRMS m/z $(\mathrm{ES}+) \mathrm{m} / z: 371[\mathrm{M}+\mathrm{H}]^{+}$

\subsubsection{Synthesis of t-butyl 2-(2-bromoethyl)piperidine-1-} carboxylate (11)

The 2-(piperidin-2-yl)ethanol 10 ( $1.55 \mathrm{mmol}, 200 \mathrm{mg}, 1$ eq.) was added to $10 \mathrm{~mL}$ mixture $(1: 1)$ of $\mathrm{CH}_{2} \mathrm{Cl}_{2}$ and $\mathrm{Na}_{2} \mathrm{CO}_{3}$ aqueous solution (10 $\mathrm{mL}$ total) in a round bottomed flask. Di-t-butyl dicarbonate $(1.70 \mathrm{mmol}, 371 \mathrm{mg}, 1.1 \mathrm{eq}$.) was added to the stirring solution. The reaction mixture was stirred for $24 \mathrm{~h}$ at room temperature. Then, the reaction mixture was diluted with $10 \mathrm{~mL}$ of water and extracted once with $10 \mathrm{~mL}$ of $\mathrm{CH}_{2} \mathrm{Cl}_{2}$ and twice with $20 \mathrm{~mL}$ of EtOAc. The combined organic layers were washed with brine, dried over $\mathrm{Na}_{2} \mathrm{SO}_{4}$ and concentrated under reduced pressure giving a yellow crude oil. The crude product was purified by chromatography on silica gel, using hexane/EtOAc (3:2) as eluent affording the $\mathrm{N}$-Boc-protected amino alcohol. Yield: $98 \%$ (314 mg). ${ }^{1} \mathbf{H}$ NMR (400 MHz CDCl 3 ) $\delta$ 4.35-4.19 (m, 1H) 3.85-3.80 (m, 2H), 3.48-3.42 (m, 1H), 3.27 (br s, 1H), 2.59-2.52 (m, 1H), $1.81(\mathrm{t}$, $J=12.0 \mathrm{~Hz}, 1 \mathrm{H}), 1.64-1.54(\mathrm{~m}, 1 \mathrm{H}), 1.51-1.37(\mathrm{~m}, 5 \mathrm{H}), 1.37(\mathrm{~s}, 9 \mathrm{H})$, 1.29-1.25 (m, 1H) ppm. ${ }^{13} \mathrm{C}$ NMR $\left(100 \mathrm{MHz} \mathrm{CDCl}_{3}\right) \delta 155.0,80.2$, 58.7, 46.1, 39.4, 32.5, 28.5, 28.4, 25.6, 19.0 ppm. LRMS $m / z(E S+) ~ m /$ $z: 230[\mathrm{M}+\mathrm{Na}]^{+}$

To a solution of the above synthesised $\mathrm{N}$-Boc-amino alcohol (0.43 mmol, $89 \mathrm{mg}$, 1eq.) in $\mathrm{CH}_{2} \mathrm{Cl}_{2}(10 \mathrm{~mL})$ was added $\mathrm{PPh}_{3}$ (0.47 mmol, $123 \mathrm{mg}, 1.1$ eq.) followed by a solution of $\mathrm{CBr}_{4}$ (0.47 mmol, $156 \mathrm{mg}, 1.1$ eq.) in $20 \mathrm{~mL}$ of $\mathrm{CH}_{2} \mathrm{Cl}_{2}$ at r.t. and the mixture was allowed to stir for $45 \mathrm{~min}$. Then, the reaction mixture was concentrated under reduced pressure giving a yellow crude oil. The obtained product was then immediately purified by chromatography on silica gel, using hexane/EtOAc (9:1) as eluent. The pure product $\mathbf{1 1}$ was obtained as a yellow oil. Yield: $79 \%(99 \mathrm{mg}) .{ }^{\mathbf{1}} \mathbf{H}$ NMR $\left(400 \mathrm{MHz} \mathrm{CDCl}_{3}\right) \delta$ 4.35-4.31 (m, 1H) 4.02-3.84 (m, 1H), $3.33-3.19(\mathrm{~m}, 2 \mathrm{H}), 2.70-2.64(\mathrm{t}, J=12.0 \mathrm{~Hz}, 1 \mathrm{H}), 2.33-2.23(\mathrm{~m}, 1 \mathrm{H})$, $1.90-1.64(\mathrm{~m}, 1 \mathrm{H}), 1.63-1.43(\mathrm{~m}, 5 \mathrm{H}), 1.40(\mathrm{~s}, 9 \mathrm{H}), 1.38-1.31(\mathrm{~m}, 1 \mathrm{H})$ ppm. ${ }^{13} \mathrm{C}$ NMR $\left(100 \mathrm{MHz} \mathrm{CDCl}_{3}\right) \delta 155.2,79.6,49.5,38.7,33.6,30.3$, 28.7, 28.5, 25.5, 19.2 ppm. LRMS $m / z(E S+) m / z: 293[\mathrm{M}+\mathrm{H}]^{+}$ 
4.1.10. General procedure for the synthesis of Boc-protected thioridazine derivatives (S12a-e)

The appropriate 2-substituted phenothiazine (5a-c) or carbazole, indole, or benzimidazole $(0.42 \mathrm{mmol}$, 1eq.) was added to $10 \mathrm{~mL}$ of DMF in a double neck round bottomed flask. $\mathrm{NaH}$ ( $0.52 \mathrm{mmol}, 12.5 \mathrm{mg}, 1.2$ eq.) was added to the stirring solution at $0{ }^{\circ} \mathrm{C}$, which then was allowed to reach r.t stirring for $20 \mathrm{~min}$. Then, t-butyl 2-(2-bromoethyl)piperidine-1-carboxylate (11) $0.52 \mathrm{mmol}$, $152 \mathrm{mg}, 1.2 \mathrm{eq}$.) and $\mathrm{NaI}(0.02 \mathrm{mmol}, 3 \mathrm{mg}, 0.1 \mathrm{eq})$ were added to the stirring solution. The reaction mixture was allowed to stir under $\mathrm{N}_{2}$ atmosphere for $12 \mathrm{~h}$ at r.t. Then, the reaction mixture was quenched with $20 \mathrm{~mL}$ of water and extracted twice with $20 \mathrm{~mL}$ of EtOAc. The combined organic layers were washed with brine, dried over $\mathrm{Na}_{2} \mathrm{SO}_{4}$ and concentrated under reduced pressure giving a yellowbrown crude oil. The crude product was purified by chromatography on silica gel, using hexane/EtOAc (4:1) as eluent.

4.1.10.1. t-Butyl 2-(2-(10H-phenothiazin-10-yl)ethyl)piperidine-1carboxylate (S12a). Yield: $45 \%$ (77 mg). ${ }^{\mathbf{1}} \mathbf{H}$ NMR (400 $\left.\mathrm{MHz} \mathrm{CDCl}_{3}\right)$ $\delta$ 7.16-7.12 (m, 4H), 6.93-6.89 (m, 2H), $6.84(\mathrm{~d}, J=8.0 \mathrm{~Hz}, 2 \mathrm{H})$, 4.45-4.35 (m, 1H), 4.08-3.96 (m, 1H), 3.92-3.74 (m, 2H), $3.38-3.28(\mathrm{~m}, 1 \mathrm{H}), 2.83-2.69(\mathrm{~m}, 1 \mathrm{H}), 2.37-2.18(\mathrm{~m}, 1 \mathrm{H}), 1.91-1.85$ $(\mathrm{m}, 1 \mathrm{H}), 1.67-1.49(\mathrm{~m}, 5 \mathrm{H}), 1.40(\mathrm{~s}, 9 \mathrm{H}) \mathrm{ppm} .{ }^{13} \mathrm{C}$ NMR $(100 \mathrm{MHz}$ $\left.\mathrm{CDCl}_{3}\right) \delta 155.1,145.3,127.6,127.3,125.1,122.5,115.3,79.4,49.5,38.7$, 33.6, 30.3, 28.7, 28.5, 25.5, 19.2 ppm. LRMS $m / z(E S+) ~ m / z: 411$ $[\mathrm{M}+\mathrm{H}]^{+}$

4.1.10.2. t-Butyl 2-(2-(2-chloro-10H-phenothiazin-10-yl)ethyl)piperidine-1-carboxylate (S12b). Yield: $61 \%(111 \mathrm{mg}){ }^{1} \mathbf{H}$ NMR (400 MHz $\left.\mathrm{CDCl}_{3}\right) \delta 7.17-7.11(\mathrm{~m}, 2 \mathrm{H}) 7.02(\mathrm{~d}, J=8.0 \mathrm{~Hz}, 1 \mathrm{H}), 6.95-6.83(\mathrm{~m}$, $3 \mathrm{H}), 6.78(\mathrm{~d}, J=4.0 \mathrm{~Hz}, 1 \mathrm{H}), 4.44-4.39(\mathrm{~m}, 1 \mathrm{H}), 4.38-4.35(\mathrm{~m}, 1 \mathrm{H})$, 4.05-4.00 (m, 1H), 3.88-3.79 (m, 2H), $2.78(\mathrm{t}, J=12 \mathrm{~Hz}, 1 \mathrm{H})$, $2.22-2.16(\mathrm{~m}, 1 \mathrm{H}), 1.90-1.81(\mathrm{~m}, 1 \mathrm{H}), 1.68-1.45(\mathrm{~m}, 5 \mathrm{H}), 1.42(\mathrm{~s}, 9 \mathrm{H})$ ppm. ${ }^{13} \mathrm{C}$ NMR $\left(100 \mathrm{MHz} \mathrm{CDCl}_{3}\right) \delta 155.2,146.7,144.6,133.4,128.1$, 127.5, 124.9, 123.0, 122.4, 115.7, 79.6, 48.8, 44.8, 39.1, 29.3, 28.5, 27.7, 25.6, $19.3 \mathrm{ppm}$. LRMS $m / z(\mathrm{ES}+) \mathrm{m} / z: 468[\mathrm{M}+\mathrm{Na}]^{+}$

4.1.10.3. t-Butyl 2-(2-(9H-carbazol-9-yl)ethyl)piperidine-1carboxylate (S12c). Yield: $61 \%(94 \mathrm{mg}) .{ }^{1} \mathbf{H}$ NMR $(400 \mathrm{MHz}$ $\left.\mathrm{CD}_{3} \mathrm{OD}\right) \delta 8.37(\mathrm{~d}, J=7.8 \mathrm{~Hz}, 2 \mathrm{H}), 7.87-7.64(\mathrm{~m}, 4 \mathrm{H}), 7.60-7.35(\mathrm{~m}$, 2H), $4.74(\mathrm{~m}, 1 \mathrm{H}), 4.69-4.59(\mathrm{~m}, 1 \mathrm{H}), 4.36-4.18(\mathrm{~m}, 1 \mathrm{H}), 3.69-3.60$ $(\mathrm{m}, 2 \mathrm{H}), 3.10-3.07(\mathrm{~m}, 1 \mathrm{H}), 2.73-2.53(\mathrm{~m}, 1 \mathrm{H}), 2.22(\mathrm{~m}, 1 \mathrm{H})$, 2.00-1.86 (m, 5H), 1.85-1.76 (m, 9H) ppm. ${ }^{13} \mathrm{C}$ NMR $(100 \mathrm{MHz}$ $\left.\mathrm{CD}_{3} \mathrm{OD}\right) \delta 155.8,140.6,140.5,125.9,125.6,123.4,123.3,120.4,120.0$, 119.1, 118.7, 110.8, 108.7, 80.1, 78.6, 40.2, 33.2, 28.5, 27.9, 27.8, 25.7, 19.1, 19.0 ppm. LRMS $m / z(\mathrm{ES}+) \mathrm{m} / z: 401[\mathrm{M}+\mathrm{Na}]^{+}$

4.1.10.4. t-Butyl 2-(2-(1H-benzo[d]imidazol-1-yl)ethyl)piperidine-1carboxylate (S12d). Yield: $63 \%$ (87 mg). ${ }^{\mathbf{1}} \mathbf{H}$ NMR (400 $\left.\mathrm{MHz} \mathrm{CDCl}_{3}\right)$ $\delta 7.91(\mathrm{~s}, 1 \mathrm{H}), 7.84-7.67(\mathrm{~m}, 1 \mathrm{H}), 7.39-7.31(\mathrm{~m}, 1 \mathrm{H}), 7.31-7.09(\mathrm{~m}$, $2 \mathrm{H}), 4.49-4.19(\mathrm{~m}, 1 \mathrm{H}), 4.10-3.90(\mathrm{~m}, 2 \mathrm{H}), 2.81-2.65(\mathrm{~m}, 1 \mathrm{H})$, $2.38-2.18(\mathrm{~m}, 1 \mathrm{H}), 1.96-1.77(\mathrm{~m}, 1 \mathrm{H}), 1.72-1.44(\mathrm{~m}, 7 \mathrm{H}), 1.44-1.29$ $(\mathrm{m}, 9 \mathrm{H}) \mathrm{ppm} .{ }^{13} \mathrm{C}$ NMR $\left(100 \mathrm{MHz} \mathrm{CDCl}_{3}\right) \delta 155.2,144.0,143.2,133.7$, 122.9, 122.1, 120.6, 109.5, 79.9, 60.4, 42.4, 30.1, 28.9, 28.5, 25.5, 19.2, $14.2 \mathrm{ppm}$. LRMS $m / z(\mathrm{ES}+) \mathrm{m} / z: 330[\mathrm{M}+\mathrm{H}]^{+}$

4.1.10.5. t-Butyl 2-(2-(1H-indol-1-yl)ethyl)piperidine-1-carboxylate (S12e). Yield: $42 \%$ (58 mg). ${ }^{\mathbf{1}} \mathbf{H}$ NMR (400 $\left.\mathrm{MHz}^{\mathrm{CDCl}} 3\right) \delta 7.62(\mathrm{~d}$, $J=8.0 \mathrm{~Hz}, 1 \mathrm{H}) 7.31(\mathrm{~d}, J=8.0 \mathrm{~Hz}, 1 \mathrm{H}), 7.22-7.18(\mathrm{~m}, 1 \mathrm{H}), 7.12-7.07$ $(\mathrm{m}, 2 \mathrm{H}), 6.48(\mathrm{~d}, J=4.0 \mathrm{~Hz}, 1 \mathrm{H}), 4.38-4.33(\mathrm{~m}, 1 \mathrm{H}), 4.15-4.03(\mathrm{~m}$, $3 \mathrm{H}), 2.81(\mathrm{t}, J=8.0 \mathrm{~Hz}, 1 \mathrm{H}), 2.31-2.21(\mathrm{~m}, 1 \mathrm{H}), 1.93-1.86(\mathrm{~m}, 1 \mathrm{H})$, $1.68-1.58(\mathrm{~m}, 6 \mathrm{H}), 1.45(\mathrm{~s}, 9 \mathrm{H}) \mathrm{ppm}{ }^{13} \mathrm{C}$ NMR $\left(100 \mathrm{MHz}_{\mathrm{CDCl}}\right)$ $\delta$ 155.2, 135.8, 128.8, 127.9, 121.5, 121.1, 119.4, 109.2, 101.2, 79.7, 43.8, 30.7, 29.0, 28.6, 25.6, 19.2 ppm. LRMS $m / z(\mathrm{ES}+) \mathrm{m} / z: 352[\mathrm{M}+\mathrm{Na}]^{+}$
4.1.11. General procedure for the synthesis of thioridazine derivatives (12a-e)

The appropriate Boc-protected compound (S12a-e) $(0.24 \mathrm{mmol}$, 1 eq.) was added to a round bottom flask containing $5 \mathrm{~mL} \mathrm{HCl}$ saturated solution in EtOAc. The reaction mixture was allowed to stir at room temperature for $24 \mathrm{~h}$. The solvent was removed under reduced pressure giving a white solid as product of the reaction. The solid products 12a-e were washed several times with cold $\mathrm{Et}_{2} \mathrm{O}$.

4.1.11.1. 10-(2-(piperidin-2-yl)ethyl)-10H-phenothiazine

(12a).

Yield: $99 \%$ (73 mg). ${ }^{1} \mathbf{H}$ NMR (400 MHz CDCl $) \delta 9.41$ (br. s., $\left.1 \mathrm{H}\right), 9.24$ (br. s., 1H), 7.15-7.12 (m, 4H), 6.92-6.86 (m, 4H), 3.97-3.92 (m, 2H), 3.49-3.45 $(\mathrm{m}, 1 \mathrm{H}), 3.08-3.05(\mathrm{~m}, 1 \mathrm{H}), 2.73-2.57(\mathrm{~m}, 1 \mathrm{H})$, $2.45-2.43(\mathrm{~m}, 1 \mathrm{H}), 2.18-2.06(\mathrm{~m}, 1 \mathrm{H}), 1.93-1.74(\mathrm{~m}, 3 \mathrm{H}), 1.69-1.60$ $(\mathrm{m}, 2 \mathrm{H}), 1.44-1.34(\mathrm{~m}, 1 \mathrm{H}) \mathrm{ppm} .{ }^{13} \mathrm{C}$ NMR $\left(100 \mathrm{MHz} \mathrm{CDCl}_{3}\right) \delta 145.3$, 127.7, 127.4, 125.4, 122.7, 115.6, 55.6, 46.8, 44.3, 33.7, 32.4, 25.9, $24.5 \mathrm{ppm}$. LRMS $\mathrm{m} / z(\mathrm{ES}+) \mathrm{m} / \mathrm{z}: 311[\mathrm{M}+\mathrm{H}]^{+}$. HRMS (ESI) $\mathrm{m} / z$ calcd. for $\mathrm{C}_{19} \mathrm{H}_{22} \mathrm{~N}_{2} \mathrm{~S}[\mathrm{M}+\mathrm{H}]$ 311.1576, found 311.1579.

4.1.11.2. Synthesis of 2-chloro-10-(2-(piperidin-2-yl)ethyl)-10Hphenothiazine (12b). Yield: $94 \%$ (77 mg). ${ }^{\mathbf{1}} \mathbf{H}$ NMR $\left(400 \mathrm{MHz} \mathrm{CDCl}_{3}\right)$ $\delta 9.54$ (br s, 1H), 9.34 (br s, 1H), 7.19 (t, $J=8.0 \mathrm{~Hz} 1 \mathrm{H}), 7.13$ (d, $J=8.0 \mathrm{~Hz}, 1 \mathrm{H}), 7.04(\mathrm{~d}, J=8.0 \mathrm{~Hz}, 1 \mathrm{H}), 6.95-6.89(\mathrm{~m}, 4 \mathrm{H}), 4.07-3.96$ (m, 2H), $3.31(\mathrm{~d}, J=8.0 \mathrm{~Hz}, 1 \mathrm{H}), 3.12-3.04(\mathrm{~m}, 1 \mathrm{H}), 2.77-2.68(\mathrm{~m}$, $1 \mathrm{H}), 2.50-2.42(\mathrm{~m}, 1 \mathrm{H}), 2.13-2.09(\mathrm{~m}, 1 \mathrm{H}), 1.85-1.69(\mathrm{~m}, 6 \mathrm{H}) \mathrm{ppm}$. ${ }^{13} \mathrm{C}$ NMR $\left(100 \mathrm{MHz} \mathrm{CDCl}_{3}\right) \delta 146.6,144.5,133.3,128.0,127.6,127.5$, 125.1, 123.9, 123.1, 122.5, 115.9, 55.4, 46.7, 44.4, 33.5, 29.7, 25.8, 24.4 ppm. LRMS $m / z(E S+) m / z: 345[\mathrm{M}+\mathrm{H}]^{+}$. HRMS (ESI) $\mathrm{m} / z$ calcd. for $\mathrm{C}_{19} \mathrm{H}_{21} \mathrm{ClN}_{2} \mathrm{~S}[\mathrm{M}+\mathrm{H}]$ 345.1187, found 345.1194.

4.1.11.3. Synthesis of 9-(2-(piperidin-2-yl)ethyl)-9H-carbazole (12c). Yield: $95 \%$ (63 mg). ${ }^{\mathbf{1}} \mathbf{H}$ NMR (400 $\left.\mathrm{MHz} \mathrm{CDCl}_{3}\right) \delta 9.66$ (br s, 1H), 9.41 (br s, $1 \mathrm{H}), 8.02(\mathrm{~d}, J=8.0,2 \mathrm{H}), 7.46-7.37(\mathrm{~m}, 4 \mathrm{H}), 7.17(\mathrm{t}, J=8.0,2 \mathrm{H})$, $4.51-4.43(\mathrm{~m}, 1 \mathrm{H}), 4.31-4.25(\mathrm{~m}, 1 \mathrm{H}), 3.38-3.36(\mathrm{~m}, 1 \mathrm{H}), 3.02-2.90$ $(\mathrm{m}, 1 \mathrm{H}), 2.70-2.67(\mathrm{~m}, 1 \mathrm{H}), 2.49-2.48(\mathrm{~m}, 1 \mathrm{H}), 2.18-2.12(\mathrm{~m}, 1 \mathrm{H})$, $1.88-1.61(\mathrm{~m}, 6 \mathrm{H}) \mathrm{ppm} .{ }^{13} \mathrm{C}$ NMR $\left(100 \mathrm{MHz} \mathrm{CDCl}_{3}\right) \delta 140.0,126.1$, 122.9, 120.4, 119.3, 108.8, 55.5, 44.9, 39.5, 32.7, 30.0, 22.3, 22.0 ppm. LRMS $\mathrm{m} / z(\mathrm{ES}+) \mathrm{m} / z: 279[\mathrm{M}+\mathrm{H}]^{+}$. HRMS (ESI) $\mathrm{m} / z$ calcd. for $\mathrm{C}_{19} \mathrm{H}_{22} \mathrm{~N}_{2}[\mathrm{M}+\mathrm{H}]$ 279.1856, found 279.1855 .

4.1.11.4. Synthesis of 1-(2-(piperidin-2-yl)ethyl)-1H-benzo[d]imidazole (12d). Yield: $90 \%$ (49 mg). ${ }^{1} \mathbf{H}$ NMR (400 $\left.\mathrm{MHz} \mathrm{CDCl}_{3}\right) \delta 10.17$ (s $1 \mathrm{H}), 9.68$ (br s, 2H), $7.82(\mathrm{t}, J=8.0 \mathrm{~Hz}, 2 \mathrm{H}), 7.44-7.36(\mathrm{~m}, 2 \mathrm{H})$, 5.01-4.79 (m, 2H), 3.46-3.43 (m, 1H), 3.36-3.25 (m, $1 \mathrm{H})$, $2.98-2.94(\mathrm{~m}, 1 \mathrm{H}), 2.85-2.71(\mathrm{~m}, 1 \mathrm{H}), 2.50-2.36(\mathrm{~m}, 1 \mathrm{H}) 1.90-1.75$ $(\mathrm{m}, 6 \mathrm{H}) \mathrm{ppm} .{ }^{13} \mathrm{C} \mathrm{NMR}\left(100 \mathrm{MHz} \mathrm{CDCl}_{3}\right) \delta$ 140.9, 130.7, 126.9, 126.7, 115.6, 112.7, 54.1, 45.0, 43.7, 33.4, 28.7, 22.3, 20.9 ppm. LRMS $m / z$ $(\mathrm{ES}+) \mathrm{m} / z: 230[\mathrm{M}+\mathrm{H}]^{+}$. HRMS (ESI) $m / z$ calcd. for $\mathrm{C}_{14} \mathrm{H}_{19} \mathrm{~N}_{3}[\mathrm{M}+\mathrm{H}]$ 230.1652 , found 230.1652 .

4.1.11.5. 1-(2-(piperidin-2-yl)ethyl)-1H-indole (12e). Yield: $94 \%$ (51 mg). ${ }^{1}$ H NMR (400 MHz CD $\left.30 D\right) \delta ~ 7.42-7.34(\mathrm{~m}, 1 \mathrm{H}), 7.24-7.19$ (m, 1H), 7.10-7.01 (m, 2H), 6.90-6.80 (m, 2H), 4.12-4.01 (m, 2H), 3.39-3.24 (m, 1H), 2.95-2.89 (m, 2H), 2.82-2.73 (m, 1H), $2.75-2.59(\mathrm{~m}, 1 \mathrm{H}), 2.49-2.40(\mathrm{~m}, 1 \mathrm{H}), 2.38-2.29(\mathrm{~m}, 2 \mathrm{H}), 1.84-1.67$ $(\mathrm{m}, 3 \mathrm{H}) \mathrm{ppm} .{ }^{13} \mathrm{C}$ NMR $\left(100 \mathrm{MHz}\left(\mathrm{CD}_{3}\right)_{2} \mathrm{SO}\right) \delta 135.8,127.9,121.8$, 121.1, 119.6, 119.1, 109.7, 54.2, 45.2, 43.6, 33.3, 28.8, 22.1, 20.8 ppm. LRMS $m / z\left(\right.$ ES + ) $m / z: 229[\mathrm{M}+\mathrm{H}]^{+}$. HRMS (ESI) $\mathrm{m} / z$ calcd. for $\mathrm{C}_{15} \mathrm{H}_{20} \mathrm{~N}_{2}[\mathrm{M}+\mathrm{H}]$ 229.1626, found 229.1701.

\subsubsection{General procedure for the synthesis of thioridazine} derivatives (13a-d)

Compounds (12a-d) $(0.14 \mathrm{mmol}, 1$ eq.) were added to a round bottom flask containing THF ( $5 \mathrm{~mL}$ ) and formaldehyde aqueous solution $37 \% \mathrm{w} / \mathrm{v}(0.28 \mathrm{mmol}, 2$ eq.). The solution was then allowed 
to stir at room temperature for $30 \mathrm{~min}$. Then, $\mathrm{NaBH}(\mathrm{AcO})_{3}$ ( $0.28 \mathrm{mmol}, 59 \mathrm{mg}, 2.0$ eq.) was added. The reaction was then stirred for $24 \mathrm{~h}$ at r.t. after which time the solution was quenched with $(20 \mathrm{~mL}) \mathrm{NaOH} 1 \mathrm{~N}$ aqueous solution. The resulting mixture was stirred for further $20 \mathrm{~min}$ and then the organic solvent was removed through reduced pressure evaporation. The residue was diluted with EtOAc, extracted twice with EtOAc $(10 \mathrm{~mL})$ and dried over anhydrous $\mathrm{MgSO}_{4}$. The solvent was concentrated under reduced pressure and the obtained product was purified by chromatography on silica gel, using EtOAc/MeOH/Et ${ }_{3} \mathrm{~N}(3.9: 1: 0.1)$ as eluent.

4.1.12.1. 10-(2-(1-Methylpiperidin-2-yl)ethyl)-10H-phenothiazine (13a). Yield: $47 \%$ (21.3 mg). ${ }^{\mathbf{1}} \mathbf{H}$ NMR (400 $\left.\mathrm{MHz} \mathrm{CDCl}_{3}\right) \delta 7.19-7.07$ $(\mathrm{m}, 4 \mathrm{H}), 6.95-6.85(\mathrm{~m}, 4 \mathrm{H}), 3.95$ (ddd, $J=13.9,8.6,5.5 \mathrm{~Hz}, 1 \mathrm{H})$, 3.89-3.77 (m, 1H), 2.89-2.72 (m, 1H), 2.22-2.16 (m, 3H), 2.16-1.99 $(\mathrm{m}, 3 \mathrm{H}), 1.93-1.80(\mathrm{~m}, 1 \mathrm{H}), 1.71(\mathrm{~d}, J=10.1 \mathrm{~Hz}, 1 \mathrm{H}), 1.64-1.50(\mathrm{~m}$, $2 \mathrm{H}), 1.34-1.18(\mathrm{~m}, 3 \mathrm{H}) \mathrm{ppm} .{ }^{13} \mathrm{C}$ NMR $\left(100 \mathrm{MHz}_{\mathrm{CDCl}}\right) \delta 145.4$, 127.6, 127.3, 125.4, 122.5, 115.6, 62.2, 57.0, 43.9, 43.1, 30.8, 30.0, 25.7, $24.2 \mathrm{ppm}$. LRMS $m / z(\mathrm{ES}+) \mathrm{m} / z: 325[\mathrm{M}+\mathrm{H}]^{+}$. HRMS (ESI) $\mathrm{m} / z$ calcd. for $\mathrm{C}_{20} \mathrm{H}_{25} \mathrm{~N}_{2} \mathrm{~S}[\mathrm{M}+\mathrm{H}]$ 325.1733, found 325.1735.

4.1.12.2. 2-Chloro-10-(2-(1-methylpiperidin-2-yl)ethyl)-10H-phenothiazine (13b). Yield: $38 \%$ (19 mg). ${ }^{\mathbf{1}} \mathbf{H}$ NMR $\left(400 \mathrm{MHz} \mathrm{CDCl}_{3}\right)$ $\delta$ 7.11-7.02 (m, 2H), $6.94(\mathrm{~d}, J=8.3 \mathrm{~Hz}, 1 \mathrm{H}), 6.85(\mathrm{t}, J=7.4 \mathrm{~Hz}, 1 \mathrm{H})$, 6.82-6.73 $(\mathrm{m}, 3 \mathrm{H}), 3.91-3.78(\mathrm{~m}, 1 \mathrm{H}), 3.78-3.63(\mathrm{~m}, 1 \mathrm{H})$, 2.85-2.68 (m, 1H), $2.14(\mathrm{~s}, 3 \mathrm{H}), 2.07-1.95(\mathrm{~m}, 3 \mathrm{H}), 1.85-1.72(\mathrm{~m}$, $1 \mathrm{H}), 1.69-1.58(\mathrm{~m}, 2 \mathrm{H}), 1.56-1.46(\mathrm{~m}, 2 \mathrm{H}), 1.28-1.11(\mathrm{~m}, 2 \mathrm{H}) \mathrm{ppm}$. ${ }^{13} \mathrm{C}$ NMR $\left(100 \mathrm{MHz} \mathrm{CDCl}_{3}\right) \delta 147.5,145.2,133.8,128.4,128.1,127.8$, 126.0, 125.1, 123.6, 122.8, 116.8, 116.5, 62.5, 57.1, 44.4, 42.3, 30.9, 29.7, 25.6, $24.1 \mathrm{ppm}$. LRMS $m / z(\mathrm{ES}+) \mathrm{m} / z: 359[\mathrm{M}+\mathrm{H}]^{+}$. HRMS (ESI) $m / z$ calcd. for $\mathrm{C}_{20} \mathrm{H}_{24} \mathrm{ClN}_{2} \mathrm{~S}[\mathrm{M}+\mathrm{H}]$ 359.1343, found 359.1347.

4.1.12.3. 9-(2-(1-Methylpiperidin-2-yl)ethyl)-9H-carbazole (13c). Yield: $67 \%(27 \mathrm{mg}) .{ }^{\mathbf{1}} \mathbf{H}$ NMR $\left(400 \mathrm{MHz} \mathrm{CDCl}_{3}\right) \delta 8.10(\mathrm{~d}, J=7.3 \mathrm{~Hz}$, $2 \mathrm{H}), 7.52-7.32(\mathrm{~m}, 4 \mathrm{H}), 7.29-7.06(\mathrm{~m}, 2 \mathrm{H}), 4.52-4.38(\mathrm{~m}, 1 \mathrm{H})$, 4.38-4.22 (m, 1H), 2.97-2.82 (m, 1H), $2.33(\mathrm{~s}, 3 \mathrm{H}), 2.17-2.06(\mathrm{~m}$, $2 \mathrm{H}), 2.06-1.94(\mathrm{~m}, 2 \mathrm{H}), 1.79(\mathrm{~d}, J=11.9 \mathrm{~Hz}, 2 \mathrm{H}), 1.67-1.60(\mathrm{~m}, 2 \mathrm{H})$, 1.40-1.27 (m, 2H) ppm ${ }^{13}$ C NMR $\left(100 \mathrm{MHz} \mathrm{CDCl}_{3}\right) \delta 140.2,125.7$, 123.0, 120.5, 118.8, 108.6, 61.7, 57.0, 43.0, 39.2, 31.5, 30.7, 25.6, 24.4 ppm. LRMS $m / z(E S+) m / z: 293[\mathrm{M}+\mathrm{H}]^{+}$. HRMS (ESI) $\mathrm{m} / z$ calcd. for $\mathrm{C}_{20} \mathrm{H}_{24} \mathrm{~N}_{2}[\mathrm{M}+\mathrm{H}]$, 293.2012 found 293.2014.

4.1.12.4. 1-(2-(1-Methylpiperidin-2-yl)ethyl)-1H-benzo[d]imidazole (13d). Yield: $70 \%(29 \mathrm{mg}) .{ }^{\mathbf{1}} \mathbf{H}$ NMR $\left(400 \mathrm{MHz} \mathrm{CD}_{3} \mathrm{OD}\right) \delta 8.86(\mathrm{~s}, 1 \mathrm{H})$, 8.33-8.22 (m, 2H), 7.99-7.90 (m, 2H), 5.03-4.95 (m, 2H), 3.55-3.50 (m, 1H), $2.90(\mathrm{~s}, 3 \mathrm{H}), 2.70-2.42(\mathrm{~m}, 4 \mathrm{H}), 2.28-2.24(\mathrm{~m}$, $2 \mathrm{H}), 2.00-1.80(\mathrm{~m}, 4 \mathrm{H}) \mathrm{ppm} .{ }^{13} \mathrm{C}$ NMR (100 MHz CD $\left.\mathrm{OD}\right) \delta 144.0$, 143.3, 134.0, 123.7, 122.9, 119.6, 110.7, 62.2, 57.1, 42.1, 32.8, 30.6, 30.1, 25.4, $24.1 \mathrm{ppm}$. LRMS $m / z(\mathrm{ES}+) \mathrm{m} / z: 244[\mathrm{M}+\mathrm{H}]^{+}$. HRMS (ESI) $m / z$ calcd. for $\mathrm{C}_{15} \mathrm{H}_{22} \mathrm{~N}_{3}[\mathrm{M}+\mathrm{H}] 244.1808$, found 244.1811.

\subsubsection{Synthesis of 1-(3-chloropropyl)-1H-indole (15)}

Indole ( $0.52 \mathrm{mmol}, 0.052 \mathrm{~mL}, 1$ eq.) was added to $10 \mathrm{~mL}$ of DMF in a double neck round bottomed flask. $\mathrm{NaH}(0.57 \mathrm{mmol}, 14 \mathrm{mg}, 1.1$ eq.) was added to the stirring solution at $0{ }^{\circ} \mathrm{C}$, and the mixture was allowed to reach r.t stirring for $20 \mathrm{~min}$. Then, 1-bromo-3chloropropane $(0.57 \mathrm{mmol}, 90 \mathrm{mg}, 1.1 \mathrm{eq}$.) was added. The reaction mixture was allowed to stir under $\mathrm{N}_{2}$ atmosphere for $12 \mathrm{~h}$ at r.t. The reaction was quenched with water $(10 \mathrm{~mL})$ and extracted twice with EtOAc $(20 \mathrm{~mL})$. The combined organic layers were washed with brine, dried over $\mathrm{Na}_{2} \mathrm{SO}_{4}$ and concentrated under reduced pressure giving a yellow-brown crude oil. The crude product (15) was purified by chromatography on silica gel, using hexane/EtOAc (4:1) as eluent. Yield: $82 \%$ (82 mg). ${ }^{\mathbf{1}} \mathbf{H}$ NMR (400 $\left.\mathrm{MHz} \mathrm{CDCl}_{3}\right) \delta 7.69$ $(\mathrm{d}, J=8.0 \mathrm{~Hz}, 1 \mathrm{H}), 7.41(\mathrm{~d}, J=8.0 \mathrm{~Hz}, 1 \mathrm{H}), 7.27(\mathrm{t}, J=8.0 \mathrm{~Hz}, 1 \mathrm{H})$, $7.19-7.15(\mathrm{~m}, 2 \mathrm{H}), 6.56(\mathrm{~d}, J=4.0 \mathrm{~Hz}, 1 \mathrm{H}), 4.37-4.33(\mathrm{~m}, 2 \mathrm{H}), 3.46(\mathrm{t}$, $J=8.0 \mathrm{~Hz}, 1 \mathrm{H}), 3.32(\mathrm{t}, J=8.0 \mathrm{~Hz}, 1 \mathrm{H}), 2.37-2.26(\mathrm{~m}, 2 \mathrm{H}) \mathrm{ppm} .{ }^{13} \mathrm{C}$ NMR $\left(100 \mathrm{MHz} \mathrm{CDCl}_{3}\right) \delta 135.9,128.8,128.1,121.8,121.2,119.6,109.4$, 101.6, 42.9, 42.0, 32.7 ppm. LRMS $m / z(E S+) m / z: 194[\mathrm{M}+\mathrm{H}]^{+}$

\subsubsection{Synthesis of 1-(3-(4-methylpiperazin-1-yl)propyl)-1H- indole (16)}

The derivative $\mathbf{1 6}$ was synthesised following the procedure used for the synthesis of compounds 7a-i. Yield: $63 \%$ (30 mg). ${ }^{\mathbf{1}} \mathbf{H}$ NMR $\left(400 \mathrm{MHz} \mathrm{CDCl}_{3}\right) \delta 7.51-7.47(\mathrm{~m}, 2 \mathrm{H}), 7.40(\mathrm{~d}, J=8.0 \mathrm{~Hz}, 1 \mathrm{H})$, $7.30-7.24$ (m, 1H), 7.19 (t, $J=8.0 \mathrm{~Hz}, 1 \mathrm{H}), 7.08(\mathrm{~d}, J=12.0 \mathrm{~Hz}, 2 \mathrm{H})$, $3.24-3.23(\mathrm{~d}, J=8.0 \mathrm{~Hz}, 2 \mathrm{H}), 2.47(\mathrm{~s}, 3 \mathrm{H}), 2.35(\mathrm{~m}, 4 \mathrm{H}), 1.46-1.41$ $(\mathrm{m}, 4 \mathrm{H}), 1.32-1.29(\mathrm{~m}, 2 \mathrm{H}) \mathrm{ppm} .{ }^{\mathbf{1 3}} \mathbf{C}$ NMR $\left(100 \mathrm{MHz} \mathrm{CDCl}_{3}\right) \delta 163.7$, $138.9,135.8,135.7,132.3,132.2,126.7,126.7,122.2,118.0,116.2,56.8$, 56.1, 25.2, 24.2, 16.0 ppm. LRMS $m / z(E S+) ~ m / z: 258[\mathrm{M}+\mathrm{H}]^{+}$HRMS (ESI) $m / z$ calcd. for $\mathrm{C}_{16} \mathrm{H}_{24} \mathrm{~N}_{3}[\mathrm{M}+\mathrm{H}]$ 258.1965, found 258.1966 .

\subsection{Biology}

Bacterial strains and growth conditions: The bacterial species used in this study were M. smegmatis mc2155 (ATCC 700084), M. bovis BCG Pasteur (ATCC 35734), M. tuberculosis mc27000, M. tuberculosis H37Rv (ATTC27294), M. tuberculosis CF73 and two MDR-TB clinical isolates (CF104 and CF81) obtained from Clemente Ferreira Hospital, Saõ Paulo, Brazil [29]. Mycobacterial species were cultured in either Middlebrook 7H9 broth or Middlebrook 7H10 agar media supplemented with albumin-dextrose-catalase (ADC) or oleic acid-albumin-dextrose-catalase (OADC) enrichments, respectively, purchased from BD Biosciences. All reagents were purchased from Sigma-Aldrich unless stated otherwise.

\subsubsection{Bacterial growth inhibition assays}

The MIC of the compounds against M. smegmatis mc2155, $M$. bovis BCG, and $M$. tuberculosis mc27000 were calculated by standard MABA (Microplate Alamar Blue assay) as previously described [27]. Briefly, $200 \mu \mathrm{L}$ of sterile deionized water was added to all outer-perimeter wells of a sterile 96-well plate (Corning Incorporated, Corning, NY) to minimize evaporation of the medium in the test wells during incubation. The wells in rows $B$ to $G$ in columns 3 to 11 received $100 \mu \mathrm{L}$ of $7 \mathrm{H} 9$ medium containing $0.2 \%$ casamino acids, $24 \mu \mathrm{g} / \mathrm{mL}$ pantothenate and 10\% OADC (Beckton Dickinson, Sparks, MD). Compounds were added to rows $B-G$ followed by $1: 2$ serial dilutions across the plate to column 10 , and $100 \mu \mathrm{L}$ of excess medium was discarded from the wells in column 10. The bacterial culture at 0.5 McFarland standard diluted 1:50 $(100 \mu \mathrm{L})$ was added to the wells in rows B to $\mathrm{G}$ in columns 2 to 11 , where the wells in column 11 served as drug-free controls. The plates were sealed with parafilmTM and were incubated at $37^{\circ} \mathrm{C}$. A freshly prepared 1:1 mixture of Alamar Blue (Celltiter-Blue ${ }^{\mathrm{TM}}$, Promega Corp, Madison, WI) reagent and 10\% Tween $^{\circledR} 80(50 \mu \mathrm{L})$ and re-incubated at $37^{\circ} \mathrm{C}$ for $24 \mathrm{~h}$.

\subsubsection{Determination of minimal inhibitory concentration ( $\mathrm{MIC}_{90}$ )}

The anti-M. tuberculosis activity of the compounds against M. tuberculosis H37Rv (ATTC27294), M. tuberculosis CF73 and two MDR-TB clinical isolates (CF104 and CF81) was determined using the Resazurin Microtiter Assay (REMA) method according to Palomino et al., [30]. Stock solutions of the tested compounds were prepared in dimethyl sulfoxide (DMSO), then diluted in Middlebrook 7H9 broth (Difco, Detroit, MI, USA) supplemented with oleic acid, albumin, dextrose and catalase (OADC enrichment) to obtain a final drug concentration range of $0.09-100 \mu \mathrm{g} / \mathrm{mL}$. A suspension of the M. tuberculosis $\mathrm{H}_{37} \mathrm{Rv}$ ATCC 27294 and clinical isolates were cultured in Middlebrook 7H9 broth supplemented with 
OADC and $0.05 \%$ Tween 80 for one week at $37^{\circ} \mathrm{C}$ in an atmosphere of $5 \% \mathrm{CO}_{2}$. The concentration was adjusted at McFarland 1 and diluted to $2.4 \times 10^{5} \mathrm{CFU} / \mathrm{mL}$. $100 \mu \mathrm{L}$ of the inoculum was added to each well of a 96-well microplate together with $100 \mu \mathrm{L}$ of the compounds. The plate was incubated for 7 days at $37{ }^{\circ} \mathrm{C}$ in an atmosphere of $5 \% \mathrm{CO}_{2}$. After $24 \mathrm{~h}, 30 \mu \mathrm{L} 0.01 \%$ resazurin (solubilized in water) was added. The fluorescence of the wells was read after $24 \mathrm{~h}$ using a Cytation $3\left(\right.$ BioTek $^{\circledR}$, Winooski, VT, USA). The MIC 90 was defined as the lowest concentration resulting in $90 \%$ inhibition of growth of $M$. tuberculosis. Samples were set up in three independent assays.

\subsubsection{Cytotoxic analysis $\left(I C_{50}\right)$ of MRC-5 cell line}

In these experiment, cells were collected in a solution of trypsin/ ethylenediamine tetracetic acid (EDTA) (Vitrocell ${ }^{\circledR}$ ) and centrifuged $(252 \times g$ for $5 \mathrm{~min}$ ). The number of cells was counted using a Neubauer chamber (Celeromics, Valencia, Spain) after staining non-viable cells with $0.4 \%$ trypan blue solution (Sigma-Aldrich ${ }^{\circledR}$ ) via the cell exclusion assay. Then, the cell concentration was adjusted to $7.5 \times 10^{4}$ cells $/ \mathrm{mL}$ in DMEM for tumor cells and MRC5 cells (ATCC CCL-171). Next, a $200 \mu \mathrm{L}$ suspension was deposited into each well of a 96-well microplate to a cell density of $1.5 \times 10^{4}$ cells/well. The cells were incubated at $37^{\circ} \mathrm{C}$ in an atmosphere of $5 \% \mathrm{CO}_{2}$ for $24 \mathrm{~h}$ to allow the cells to attach to the plate [31]. The compounds were solubilized in DMSO to an initial concentration of $10,000 \mu \mathrm{g} / \mathrm{mL}$. Test solutions of the compounds were prepared to obtain concentrations from 500 to $1.95 \mu \mathrm{g} / \mathrm{mL}$. The diluted solutions were added to the cells after changing the medium to remove any non-adherent cells, and the cultures were incubated for an additional $24 \mathrm{~h}$. The cytotoxicity of the compounds was determined after incubating the cells in $30 \mu \mathrm{L}$ of resazurin for approximately $2 \mathrm{~h}$. The measurement was performed using a Synergy H1 microplate reader (BioTek ${ }^{\circledR}$, Winooski, VT, USA) with excitation and emission filters at wavelengths of 530 and $590 \mathrm{~nm}$, respectively. The assays were performed in three independent experiments.

\subsubsection{Cytotoxicity assay (IC 50$)$ of J774 cell line}

In vitro cytotoxicity assays ( $\mathrm{IC}_{50}$ ) were performed on the J774 cell line, as previously reported [32]. The cells were routinely maintained in Complete Medium (RPMI-1640 supplemented with $10 \%$ heat-inactivated fetal bovine serum (FBS); $100 \mathrm{U} / \mathrm{mL}$ penicillin and $100 \mu \mathrm{g} / \mathrm{mL}$ streptomycin), at $37{ }^{\circ} \mathrm{C}$, in a humidified $5 \% \mathrm{CO}_{2}$ atmosphere. After reaching confluence, the cells were detached and counted. For the cytotoxicity assay, $1 \times 10^{5}$ cells $/ \mathrm{mL}$ were seeded in $200 \mu \mathrm{L}$ of Complete Medium in 96-well plates (NUNC). The plates were incubated at $37{ }^{\circ} \mathrm{C}$ under a $5 \% \mathrm{CO}_{2}$ atmosphere for $24 \mathrm{~h}$, to allow cell adhesion prior to drug testing. The compounds were dissolved in DMSO and subjected to two-fold serial dilution from 1250 to $3.9 \mu \mathrm{g} / \mathrm{mL}$. Cells were exposed to the compounds at various concentrations for a 24 h-period. Resazurin solution was then added to the cell cultures and incubated for $6 \mathrm{~h}$. Cell respiration, as an indicator of cell viability, was detected by reduction of resazurin to resorufin, whose pink colour and fluorescence indicates cell viability. A persistent blue colour of resazurin is a sign of cell death. The fluorescence measurements $(530 \mathrm{~nm}$ excitation filter and $590 \mathrm{~nm}$ emission filter) were performed in a SPECTRAfluor Plus (Tecan) microfluorimeter. The IC 50 value was defined as the highest drug concentration at which $50 \%$ of the cells are viable relative to the control.

\subsubsection{Efflux pump inhibition assays}

The assay was performed based on previously published protocols [27]. In brief, early log phase cells of $M$. smegmatis were taken and the $\mathrm{OD}_{600}$ was adjusted to 0.4 in $1 \times$ PBS. The test samples contained (4-6) $\times 10^{7}$ bacteria/mL in PBS, $0.4 \%$ glucose (as a source of energy for efflux pumps activity), $0.5 \mathrm{mg} / \mathrm{L}$ ethidium bromide (as a substrate for efflux pumps), and the compounds being tested at 1/ $4 \times$ MIC concentrations. Blank samples contained all of the components mentioned above, except the bacterial suspension, which was replaced with $1 \times$ PBS. Verapamil and chlorpromazine, known efflux pump inhibitors, were used as positive controls at concentrations of $125 \mu \mathrm{g} / \mathrm{mL}$ and $10 \mu \mathrm{g} / \mathrm{mL}$ respectively. The experiment was performed in a 96-well plates that was read in a fluorimeter (FLUOstar OPTIMA, BMG Labtech) with the following parameters: wavelengths of 544 and $590 \mathrm{~nm}$ for excitation and detection of fluorescence, gain 2200 , a temperature of $37{ }^{\circ} \mathrm{C}$, and a cycle of measurement every minute for a total period of $60 \mathrm{~min}$. The accumulation or efflux of ethidium bromide was monitored in realtime for the mentioned period.

\section{Acknowledgements}

Northumbria University is gratefully acknowledged for financial support. DC thanks Royal Society of Chemistry (Research Fund 2015). AM thanks Birkbeck Anniversary/Wellcome Trust PhD studentship.

\section{Appendix A. Supplementary data}

Supplementary data related to this article can be found at http:// dx.doi.org/10.1016/j.ejmech.2016.12.042.

\section{References}

[1] http://www.who.int/tb/publications/global_report/en/.

[2] E.W. Tiemersma, M.J. van der Werf, M.W. Borgdorff, B.G. Williams, N.J.D. Nagelkerke, Natural history of tuberculosis: duration and fatality of untreated pulmonary tuberculosis in HIV negative patients: a systematic review, PLoS One 6 (2011) e17601.

[3] C. Geldmacher, A. Zumla, M. Hoelscher, Interaction between HIV and Mycobacterium tuberculosis: HIV-1-induced CD4 T-cell depletion and the development of active tuberculosis, Curr. Opin. HIV AIDS 7 (2012) 268-274.

[4] a) R.D. Deshmukh, D.J. Dhande, K.S. Sachdeva, A. Sreenivas, A.M.V. Kumar, S. Satyanarayana, M. Parmar, P.K. Moonan, T.Q. Lo, Patient and provider reported reasons for lost to follow up in MDRTB treatment: a qualitative study from a drug resistant TB Centre in India, PLoS One 10 (2015) e0135802; b) A. Maitra, T.K. Kamil, M. Shaik, C.A. Danquah, A. Chrzastek, S. Bhakta, Early diagnosis and effective treatment regimens are the keys to tackle antimicrobial resistance in tuberculosis (TB): a report from Euroscicon's international TB Summit 2016, Virulence (2016) 1-4.

[5] J.A. Caminero, Treatment of multidrug-resistant tuberculosis:evidence and controversies, Int. J. Tuberc. Lung Dis. 10 (2006) 829-837.

[6] E.D. Chan, V. Laurel, M.J. Strand, J.F. Chan, M.L. Huynh, M. Goble, M.D. Iseman, Treatment and outcome analysis of 205 patients with multidrug-resistant tuberculosis, Am. J. Respir. Crit. Care Med. 169 (2004) 1103-1109.

[7] B. Eker, J. Ortmann, G.B. Migliori, G. Sotgiu, R. Muetterlein, R. Centis, H. Hoffmann, D. Kirsten, T. Schaberg, S. Ruesch-Gerdes, C. Lange, Multidrugand extensively drug-resistant tuberculosis, Emerg. Infect. Dis, 14 (2008) 1700-1706.

[8] C.D. Mitnick, S.S. Shin, K.J. Seung, M.L. Rich, S.S. Atwood, J.J. Furin, G.M. Fitzmaurice, F.A. Alcantara Viru, S.C. Appleton, J.N. Bayona, C.A. Bonilla, K. Chalco, S. Choi, M.F. Franke, H.S. Fraser, D. Guerra, R.M. Hurtado, D. Jazayeri, K. Joseph, K. Llaro, L. Mestanza, J.S. Mukherjee, M. Munñoz, E. Palacios, E. Sanchez, A. Sloutsky, M.C. Becerra, Comprehensive treatment of extensively drug-resistant tuberculosis, N. Engl. J. Med. 359 (2008) 563-574.

[9] A.A. Velayati, P. Farnia, M.R. Masjedi, The totally drug resistant tuberculosis (TDR-TB), Int. J. Clin. Exp. Med. 6 (2013) 307-309.

[10] K. Hards, J.R. Robson, M. Berney, L. Shaw, D. Bald, A. Koul, K. Andries, G.M. Cook, Bactericidal mode of action of bedaquiline, J. Antimicrob. Chemother. 70 (2014) 2028-2037.

[11] B. Chan, T.M. Khadem, J. Brown, A review of tuberculosis: focus on bedaquiline, Am. J. Heal. Pharm. 70 (2013) 1984-1994.

[12] M. Protopopova, C. Hanrahan, B. Nikonenko, R. Samala, P. Chen, J. Gearhart, L. Einck, C.A. Nacy, Identification of a new antitubercular drug candidate, SQ109, from a combinatorial library of 1,2-ethylenediamines, J. Antimicrob. Chemother. 56 (2005) 968-974.

[13] Q. Ruan, Q. Liu, F. Sun, L. Shao, J. Jin, S. Yu, J. Ai, B. Zhang, W. Zhang, Moxifloxacin and gatifloxacin for initial therapy of tuberculosis: a meta-analysis of randomized clinical trials, Emerg. Microbes Infect. 5 (2016) e12. 
[14] M. Lee, J. Lee, M.W. Carroll, H. Choi, S. Min, T. Song, L.E. Via, L.C. Goldfeder, E. Kang, B. Jin, H. Park, H. Kwak, H. Kim, H.S. Jeon, I. Jeong, J.S. Joh, R.Y. Chen, K.N. Olivier, P.A. Shaw, D. Follmann, S.D. Song, J.K. Lee, D. Lee, C.T. Kim, V. Dartois, S.K. Park, S.N. Cho, C.E. Barry III, Linezolid for treatment of chronic extensively drug-resistant tuberculosis, N. Engl. J. Med. 367 (2012) $1508-1518$.

[15] J.C. Johnston, N.C. Shahidi, M. Sadatsafavi, J.M. Fitzgerald, Treatment outcomes of multidrug-resistant tuberculosis: a systematic review and meta-analysis, PLoS One 4 (2009) 0006914.

[16] L. Amaral, M. Viveiros, J.E. Kristiansen, "Non-Antibiotics": alternative therapy for the management of MDRTB and MRSA in economically disadvantaged countries, Curr. Drug Targets 7 (2006) 887-891.

[17] O.Y. Limanskaya, T.N. Mukhina, V.N. Stepanshina, I.G. Shemyakin, X. Wu, J. Zhang, T.V. Fesenko, V.A. Pokrovskiy, A.P. Limanskii, Identification of wildtype Mycobacterium tuberculosis isolates and point mutations associated with isoniazid resistance, Mol. Biol. 44 (2010) 559-567.

[18] L. Amaral, J.E. Kristiansen, M. Viveiros, J. Atouguia, Activity of phenothiazines against antibiotic-resistant Mycobacterium tuberculosis: a review supporting further studies that may elucidate the potential use of thioridazine as antituberculosis therapy, J. Antimicrob. Chemother. 47 (2001) 505-511.

[19] L. Amaral, J. Molnar, Why and how the old neuroleptic thioridazine cures the XDR-TB patient, Pharm. (Basel) 5 (2012) 1021-1031.

[20] L. Amaral, J. Molnar, Potential therapy of multidrug-resistant and extremely drug-resistant tuberculosis with thioridazine, Vivo (Brooklyn) 26 (2012) $231-236$.

[21] L. Rodrigues, J. Ramos, I. Couto, L. Amaral, M. Viveiros, Ethidium bromide transport across Mycobacterium smegmatis cell-wall: correlation with antibiotic resistance, BMC Microbiol. 11 (2011) 35.

[22] D. Machado, I. Couto, J. Perdigo, L. Rodrigues, I. Portugal, P. Baptista, B. Veigas, L. Amaral, M. Viveiros, Contribution of efflux to the emergence of isoniazid and multidrug resistance in Mycobacterium tuberculosis, PLoS One 7 (2012) 0034538.

[23] J. de Keijzer, A. Mulder, P.E.W. de Haas, A.H. de Ru, E.M. Heerkens, L. Amaral, D. van Soolingen, P.A. van Veelen, Thioridazine alters the cell-envelope permeability of Mycobacterium tuberculosis, J. Proteome Res. 15 (2016) 1776-1786.

[24] M. Martins, Z. Schelz, A. Martins, J. Molnar, G. Hajs, Z. Riedl, M. Viveiros,
I. Yalcin, E. Aki-Sener, L. Amaral, In vitro and ex vivo activity of thioridazine derivatives against Mycobacterium tuberculosis, Int. J. Antimicrob. Agents 29 (2007) 338-340.

[25] F. Schlauderer, K. Lammens, D. Nagel, M. Vincendeau, A.C. Eitelhuber S.H.L. Verhelst, D. Kling, A. Chrusciel, J. Ruland, D. Krappmann, K.-P. Hopfner Structural analysis of phenothiazine derivatives as allosteric inhibitors of the MALT1 paracaspase, Angew. Chem. Int. Ed. 52 (2013) 10384-10387.

[26] The N-methylated indole analogues of $12 \mathrm{e}$ were previously shown to be not active against MTB M. Pieroni, D. Machado, E. Azzali, S. Santos Costa, I. Couto, G. Costantino, M. Viveiros, Rational design and synthesis of thioridazine analogues as enhancers of the antituberculosis therapy, J. Med. Chem. 58 (2015) $5842-5853$

[27] S. Bhakta, N. Scalacci, A. Maitra, A.K. Brown, S. Dasugari, D. Evangelopoulos, T.D. McHugh, P.N. Mortazavi, A. Twist, E. Petricci, F. Manetti, D. Castagnolo, Design and Synthesis of 1-((1,5-bis(4-chlorophenyl)-2-methyl-1H-pyrrol-3yl)methyl)-4-methylpiperazine (BM212) and N-adamantan-2-yl-N'-((E)-3,7dimethylocta-2,6-dienyl)ethane-1,2-diamine (SQ109) pyrrole hybrid derivatives: discovery of potent antitubercular agents effective against multidrug-resistant mycobacteria, J. Med. Chem. 59 (2016) 2780-2793.

[28] E. Pelizzetti, E. Mentasti, Cation radicals of phenothiazines. Electron transfer with aquoiron(II) and -(III) and hexacyanoferrate(II) and -(III), Inorg. Chem. 18 (1979) 583-588.

[29] M. Miyata, F.R. Pavan, D.N. Sato, L.B. Marino, M.H. Hirata, R.F. Cardoso, F.A. de Melo, C.F. Zanelli, C.Q. Leite, Drug resistance in Mycobacterium tuberculosis clinical isolates from Brazil: phenotypic and genotypic methods, Biomed Pharmacother. 65 (2011) 456-459.

[30] J. Palomino, A. Martin, M. Camacho, H. Guerra, J. Swings, F. Portaels, Resazurin microtiter assay Plate: simple and inexpensive method for detection of drug resistance in Mycobacterium tuberculosis, Antimicrob. Agents Chemother. 46 (2002) 2720-2722.

[31] J. O'Brien, I. Wilson, T. Orton, F. Pognan, Investigation of the Alamar Blue (resazurin) fluorescent dye for the assessment of mammalian cell cytotoxicity Eur. J. Biochem. 267 (2000) 5421-5426.

[32] F.R. Pavan, P.I. da S Maia, S.R. Leite, V.M. Deflon, A.A. Batista, D.N. Sato, S.G. Franzblau, C.Q. Leite, Thiosemicarbazones, semicarbazones, dithiocarbazates and hydrazide/hydrazones: anti-Mycobacterium tuberculosis activity and cytotoxicity, Eur. J. Med. Chem. 45 (2010) 1898-1905. 